\title{
Predicting the mineral composition of dust aerosols - Part 1: Representing key processes
}

\author{
J. P. Perlwitz ${ }^{1,2, *}$, C. Pérez García-Pando ${ }^{1,2, *}$, and R. L. Miller ${ }^{2,1, *}$ \\ ${ }^{1}$ Department of Applied Physics and Applied Mathematics, Columbia University in the City of New York, NY, USA \\ ${ }^{2}$ NASA Goddard Institute for Space Studies, New York, NY, USA \\ *All authors contributed equally to this work.
}

Correspondence to: J. P. Perlwitz (jan.p.perlwitz@ nasa.gov)

Received: 17 December 2014 - Published in Atmos. Chem. Phys. Discuss.: 6 February 2015

Revised: 8 September 2015 - Accepted: 28 September 2015 - Published: 21 October 2015

\begin{abstract}
Soil dust aerosols created by wind erosion are typically assigned globally uniform physical and chemical properties within Earth system models, despite known regional variations in the mineral content of the parent soil. Mineral composition of the aerosol particles is important to their interaction with climate, including shortwave absorption and radiative forcing, nucleation of cloud droplets and ice crystals, heterogeneous formation of sulfates and nitrates, and atmospheric processing of iron into bioavailable forms that increase the productivity of marine phytoplankton. Here, aerosol mineral composition is derived by extending a method that provides the composition of a wet-sieved soil. The extension accounts for measurements showing significant differences between the mineral fractions of the wetsieved soil and the emitted aerosol concentration. For example, some phyllosilicate aerosols are more prevalent at silt sizes, even though they are nearly absent at these diameters in a soil whose aggregates are dispersed by wet sieving. We calculate the emitted mass of each mineral with respect to size by accounting for the disintegration of soil aggregates during wet sieving. These aggregates are emitted during mobilization and fragmentation of the original undispersed soil that is subject to wind erosion. The emitted aggregates are carried far downwind from their parent soil. The soil mineral fractions used to calculate the aggregates also include larger particles that are suspended only in the vicinity of the source. We calculate the emitted size distribution of these particles using a normalized distribution derived from aerosol measurements. In addition, a method is proposed for mixing minerals with small impurities composed of iron oxides. These mixtures are important for transporting iron far from the dust
\end{abstract}

source, because pure iron oxides are more dense and vulnerable to gravitational removal than most minerals comprising dust aerosols. A limited comparison to measurements from North Africa shows that the model extensions result in better agreement, consistent with a more extensive comparison to global observations as well as measurements of elemental composition downwind of the Sahara, as described in companion articles.

\section{Introduction}

Climate perturbations by soil dust aerosols created by wind erosion depend fundamentally upon the physical and chemical properties of the aerosol particles. However, Earth system models typically assume that soil dust aerosols have globally uniform composition, despite known regional variations in the mineral composition of the parent soil. Perturbations by dust to the energy and water cycles depend upon aerosol radiative forcing (Miller et al., 2004, 2014; Perlwitz and Miller, 2010), whose solar component is strongly related to the presence of iron oxides (Sokolik and Toon, 1996, 1999; Tegen et al., 1997; Redmond et al., 2010; Wagner et al., 2012; Moosmüller et al., 2012). Forcing at thermal wavelengths also varies with source mineral content (Turner, 2008). Absorption of solar radiation by dust alters the photolysis of ozone (Bian et al., 2003) while influencing chemical reactions of other trace gases (Goodman et al., 2000; Usher et al., 2003; Chen et al., 2011). The rates of heterogeneous chemical reactions on the dust particle surface that form coatings of sulfate, nitrate, chloride, or organics during atmospheric 
transport depend on the dust mineral and chemical composition (Dentener et al., 1996; Russell et al., 2002; Bian and Zender, 2003; Krueger et al., 2004; Bauer and Koch, 2005; Sullivan et al., 2007; Matsuki et al., 2010; Rubasinghege et al., 2013). Dust aerosols influence cloud formation (and the associated radiative forcing) by serving as nucleation sites for cloud droplets and ice crystals (Johnson, 1982; Feingold et al., 1999; Sassen, 2002; DeMott et al., 2003; Twohy et al., 2009; Seifert et al., 2010). The nucleation properties of dust depend upon their hygroscopicity and shape that in turn depend upon their mineral composition (Frinak et al., 2005; Kelly et al., 2007; Hatch et al., 2008; Ma et al., 2012; Hatch et al., 2014; Zimmermann et al., 2008; Hoose and Möhler, 2012; Murray et al., 2012; Atkinson et al., 2013; YakobiHancock et al., 2013). Bioavailable iron within dust, transported to remote regions and processed during transport (Shi et al., 2011; Takahashi et al., 2011; Ito, 2012), catalyzes photosynthesis by ocean phytoplankton, increasing carbon dioxide uptake and influencing the global carbon cycle (Jickells et al., 2005; Maher et al., 2010; Shi et al., 2012; Schulz et al., 2012). Dust is associated with respiratory and cardiovascular disease, along with epidemics of meningococcal meningitis in the African Sahel (Pérez García-Pando et al., 2014a, b), where iron from dust particles may foster bacterial growth and weaken the immune system.

Deriving aerosol mineral composition requires global knowledge of soil mineral content. Claquin et al. (1999) proposed that the soil mineral fractions are approximately related to the soil type, which is available from global atlases (see also Nickovic et al., 2012; Journet et al., 2014). However, Claquin et al. (1999) noted that the mineral content of the emitted aerosol may differ from that of the parent soil. Measurements of mineral fractions are based upon wet sedimentation (or "wet sieving") techniques that disturb the soil sample, breaking aggregates that are found in the original, undispersed soil that is subject to wind erosion. Wet sieving alters the soil size distribution, replacing aggregates that are potentially mobilized as aerosols with a collection of smaller particles (Shao, 2001; Choate et al., 2006; Laurent et al., 2008). Size-resolved measurements of emission show that silt sizes are mobilized in a greater proportion compared to clay (e.g., Gillette et al., 1974; Sow et al., 2009; Kok, 2011b). Minerals like phyllosilicates that are commonly emitted as aggregates will be underestimated where their size distribution is characterized after wet sieving.

The challenge remains to derive mineral fractions of the emitted dust based upon their fractions measured in wetsieved soils. Previous attempts to predict the aerosol mineral composition have generally neglected the effects of wet sieving (Hoose et al., 2008; Atkinson et al., 2013; Journet et al., 2014). Calculation of how the particle size distribution and mineral composition of the soil are modified during emission is complicated (e.g., Shao, 2001; Alfaro and Gomes, 2001; Grini et al., 2002), although recent studies have proposed simplifications (Kok, 2011b; Scanza et al., 2015). Fi- nally, representations of aerosol mineral composition need to account for mixtures of minerals. Examination of individual particles shows that iron, an element that is central to many climate processes, is often found as trace impurities of iron oxide attached to aggregates of other minerals (Reid et al., 2003; Scheuvens et al., 2011; Lieke et al., 2011; Deboudt et al., 2012; Scheuvens and Kandler, 2014).

In this article, we propose a model of dust mineral composition to address these challenges. Some of the extensions of our model have been introduced previously (Kok, 2011b; Scanza et al., 2015). In Sect. 2, we use measurements of the fully dispersed soil to calculate the emitted size distribution of each mineral. We also calculate mixtures of minerals with iron oxides to account for the transport of iron to remote regions. In Sect. 3, we describe simulations with the NASA Goddard Institute for Space Studies (GISS) Earth System ModelE2 that show the effect of our extensions. In Sect. 4, we describe the geographical distribution of emission and surface concentration for each mineral and its mixture with iron oxide, while using an intermediate model version to identify the origin of improved behavior in our new model that is documented here and in the companion articles. We summarize the new features of our model in Sect. 5.

Our model extensions are motivated by observations. In Sect. 4, we show that our new model is in better agreement with aerosol measurements at a site in North Africa after accounting for the effects of wet sieving. Detailed comparison of the model to a broader array of observations is deferred to companion articles. In Perlwitz et al. (2015), we compare our predicted aerosol distribution to a new global compilation of mineral measurements from nearly sixty studies. In Pérez García-Pando et al. (2015), we evaluate our results using observations from the Izaña Observatory, where elemental composition of Saharan dust has been measured for the past decade.

\section{The mineralogical dust cycle model}

\subsection{Overview}

\subsubsection{Modeling challenges}

Our aim is to predict regional variations of aerosol mineral composition as a function of particle size. For comparison, ModelE2 currently predicts the size distribution of dust aerosols, but assumes a globally uniform mineral content (Miller et al., 2006). Regional variations in soil mineral composition lead to variations in dust aerosol composition. However, deriving aerosol mineral content also requires knowledge of how the size distribution of the parent soil is transformed during the emission process. Here, we discuss some of these challenges, before describing our algorithm in Sect. 2.2. 
Claquin et al. (1999) proposed that soil mineral content is related to the soil type provided by the Digital Soil Map of the World (DSMW), compiled by the Food and Agriculture Organization (FAO) of the United Nations (FAO, 1995, 2007). For the clay-sized fraction of the soil (with particle diameters up to $2 \mu \mathrm{m}$ ), the DSMW soil type is used to estimate the fractional composition of phyllosilicates (illite, kaolinite and smectite) along with calcite and quartz. Similarly, for the silt-sized soil fraction (with diameters between 2 and $50 \mu \mathrm{m}$ ), soil type is used to estimate the fractional composition of calcite, quartz, feldspar, gypsum and hematite. These minerals were chosen because of their relative abundance and potential importance to climate and biogeochemical processes, although other minerals are present in arid soils. The relation between soil type and fractional mineral abundance within the clay and silt-size categories is summarized in the Mean Mineralogical Table (MMT; Table 2 from Claquin et al., 1999). Subsequent studies have refined the proposed relation between soil type and mineral composition (Nickovic et al., 2012; Journet et al., 2014). Estimating the soil mineral composition additionally requires information about the fraction of clay and silt-sized particles present at each location, available from global databases of soil texture (Webb et al., 1993; Reynolds et al., 2000; Shangguan et al., 2014).

Claquin et al. (1999) note that their MMT introduces various sources of uncertainty for dust aerosol modeling. First, the relation between mineral composition and soil type is derived from a limited number of measurements that are particularly scarce in the arid and semi-arid areas that contain dust sources. Second, this relation assumes that regional variations in mineral content within a particular soil type can be neglected. Third, measurements are based on wet sedimentation ("wet sieving") techniques that disturb the soil samples, breaking the aggregates that are found in the original, undispersed soil that is subject to wind erosion. Wet sieving alters the soil size distribution, replacing aggregates with a collection of smaller particles (Shao, 2001; Choate et al., 2006; Laurent et al., 2008). Techniques that minimize the breaking of the aggregates (McTainsh et al., 1997; Marticorena et al., 1997) are available to characterize the size distributions of North African and Chinese soil samples (Chatenet et al., 1996; Mei et al., 2004). However, these measurements remain very limited, are based upon a variety of analytical methods (Laurent et al., 2008), and provide the size distribution of only the bulk soil rather than distinguishing among individual minerals. Wet sieving is also used to characterize the soil texture in global data sets that give the fraction of clay, silt and sand-sized particles at each location (e.g., Shangguan et al., 2014). Claquin et al. (1999) emphasize that differences in the mineral size distribution between wet-sieved soils and the emitted aerosol particles are potentially important and merit further examination. In the absence of knowledge about this difference, previous studies have assumed that the emitted size distribution of each mineral closely resembles that of the wet-sieved soil (Claquin et al., 1999; Hoose et al., 2008; Atkinson et al., 2013; Journet et al., 2014).

Differences between the size distribution of the soil after wet sieving and during emission are potentially large. Figure 1 shows the volume distribution as a function of particle size for common airborne minerals at Tinfou, Morocco, during the Saharan Mineral Dust Experiment (SAMUM) campaign of 2006 (Kandler et al., 2009). Calculation of these distributions is described in the Supplement. Each particle consists of a single mineral or aggregates of different minerals. For example, images suggest that iron oxides are consistently present both in pure crystalline form and as small impurities attached to other minerals (e.g., Fig. 2.1f and g of Scheuvens and Kandler, 2014). Figure 1 distinguishes between conditions of high and low aerosol concentration. The main difference between the two conditions is that larger-sized particles are missing from the low-concentration events (Fig. 1, top row), suggesting that these particles have been removed during gravitational settling following their mobilization at a distant source. In contrast, the presence of larger particles at times of high concentration (Fig. 1, bottom row) suggests that this size distribution is a better indicator of the emitted size distribution.

Figure 1 shows that the mass of phyllosilicate aerosols like illite and kaolinite is predominantly within silt particle sizes. That is, phyllosilicate aerosols that are nominally "clay" minerals are observed mainly at larger silt sizes. This is corroborated by aerosol measurements at other locations where clay aggregates routinely exceed $2 \mu \mathrm{m}$ in particle diameter (e.g., Leinen et al., 1994; Arnold et al., 1998; Reid et al., 2003; Alastuey et al., 2005; Jeong and Nousiainen, 2014). Wet sieving breaks up these larger particles, and models that do not account for this potentially allow a significant fraction of phyllosilicates to travel unrealistically far from their source as a result of insufficient gravitational deposition. This has implications for the delivery of phyllosilicate iron to fertilize photosynthesis within distant marine ecosystems (Journet et al., 2008).

The presence of significant clay mass at silt diameters argues that aggregates in the original soil subject to wind erosion are significantly dispersed by wet sieving. The alteration of the carbonate size distribution during emission (Caquineau et al., 1998) suggests that they too are modified during the soil analyses used to construct the MMT. An important challenge is thus to calculate the emitted size distribution of each mineral, given that information is only available about the fully dispersed soil.

Direct entrainment by the wind of the smaller soil particles that travel thousands of kilometers downwind from their source (whose diameters are generally below $20 \mu \mathrm{m}$ ) is hindered by the cohesive force that binds adjacent particles (Iversen et al., 1976). Larger soil grains or aggregates are more easily lifted because this cohesion can be overcome by the wind stress acting over a larger area (Iversen and White, 1982; Shao and Lu, 2000). 


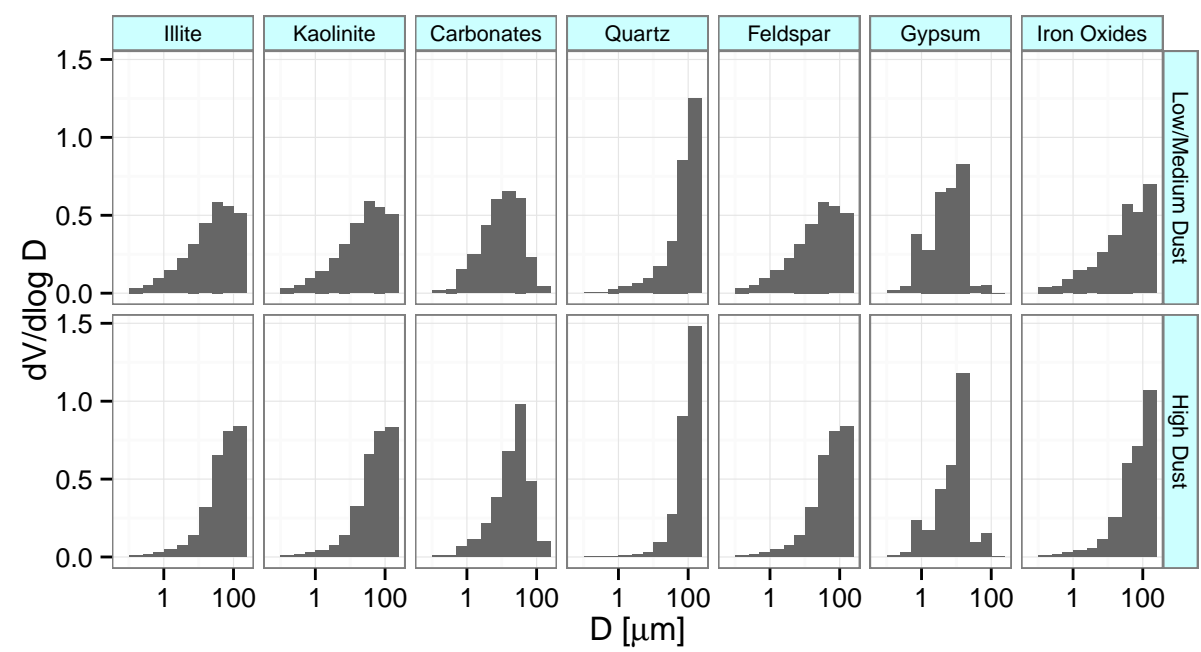

Figure 1. Volume distribution of minerals with respect to particle diameter, calculated as described in the Supplement, using size-resolved dust number and volume fraction measured by Kandler et al. (2009). The size bins correspond to the following range of particle diameter $(\mu \mathrm{m}): 0.1-0.25 ; 0.25-0.5 ; 0.5-1.0 ; 1.0-2.5 ; 2.5-5.0 ; 5.0-10.0 ; 10.0-25.0 ; 25.0-50.0 ; 50.0-100.0 ; 100.0-250.0$. Upper panel: low/medium dust concentration; lower panel: high dust concentration. The size distribution is normalized so that the total volume is unity for each mineral.

Most of the smaller particles that are transported globally are entrained into the atmosphere during the fragmentation of aggregates that are bombarded by larger particles, or else are large enough to be lifted directly by the wind and disintegrated through repeated collisions (Shao et al., 1993; Kok, 2011b; Marticorena, 2014). Fragmentation is an important source of clay-sized aerosols, although the abundance of phyllosilicate mass at silt sizes in Fig. 1 makes it clear that many soil aggregates are not completely disintegrated into clay-sized aerosols during mobilization.

An additional modeling challenge is that different minerals may have different size distributions in the soil and may not be equally susceptible to disaggregation and fragmentation during wet sieving and emission, respectively. The size distribution of each mineral in Fig. 1 is normalized with respect to its total volume, allowing comparison of the characteristic particle size between different minerals. For example, Fig. 1 shows that a greater fraction of quartz mass is found at large particle sizes, compared to other minerals. Differences in the aerosol size distribution among minerals may result from contrasting size distributions in the parent soil as well as different aggregation and fragmentation properties of each mineral. A model must account for these contrasts to reproduce observations that far-travelled aerosols are depleted in quartz compared to the fraction of this mineral in the parent soil (Glaccum and Prospero, 1980; Jeong, 2008).

In Sect. 2.2, we describe a method to calculate the mineral composition of soil dust aerosols. We begin by calculating regional variations in the soil mineral content following Claquin et al. (1999), through a combination of an MMT and a global atlas of soil texture. We propose two extensions to address assumptions noted by that study. First, we describe a semi-empirical method that follows Kok (2011b) to calcu- late the size distribution of emitted minerals based upon measurements of the soil after dispersion by wet sieving. This extension is described in more detail in Sect. 2.1.2.

Our second extension is to account for mixtures of minerals that are often observed within a single aerosol particle (Kandler et al., 2011; Scheuvens and Kandler, 2014; Jeong and Nousiainen, 2014). For example, iron oxides are often present as small impurities within other minerals (Kandler et al., 2007; Scheuvens et al., 2011). Representation of mixtures imposes a potentially large computational burden. For example, the number of combinations consisting solely of mineral pairs increases geometrically with the number of represented minerals.

For minerals removed from the atmosphere at the same rate, their combination can be represented as an external mixture, requiring no additional prognostic variables. In this case, the mineral fraction at a particular size is interpreted as the fractional mass of that mineral that is present either in pure form or as an aggregate. In the latter case, it is the diameter of the aggregate that is used to assign a size category. As an example, a $25 \%$ mass fraction of illite in the 4 to $8 \mu \mathrm{m}$ category means that the particles within this size range consist on average of $25 \%$ illite by mass. (By treating mineral combinations as external mixtures, we do not explicitly track the mass fractions of individual aggregate particles, so a fraction of $25 \%$ at a particular location might represent a combination of particles with 20 and $95 \%$ illite, for example.) In this example, the particle diameter does not represent the dimension of the aggregated illite, whose diameter is smaller and possibly outside of this size category. Instead, it is the composite particles containing illite (aggregated with other minerals) that have diameters within the 4 to $8 \mu \mathrm{m}$ size category. This interpretation is consistent with the measurements 
of Kandler et al. (2009), whose mass fractions represent the contribution of each mineral to particles of a particular size and not the size distribution of individual minerals.

The rate of aerosol removal is distinguished in part by particle density that controls the speed of gravitational settling. Many minerals commonly observed to comprise dust particles have similar densities, suggesting that external mixing is a reasonable idealization that is attractive for its computational simplicity. Mineral fractions also evolve during wet scavenging as a result of contrasts in mineral solubility and during gravitational settling through contrasts in particle shape. We neglect both sources of complexity in the present study, although Li and Osada (2007) suggest that the latter effect is important near source areas.

In contrast, iron oxides like hematite and goethite have densities that are twice that of the other minerals, and would thus be removed by gravitational settling within roughly half the distance from their source. This density contrast means that mineral combinations containing iron oxides cannot be represented implicitly as external mixtures like combinations of other minerals. Iron oxide mixtures must be treated explicitly as separate prognostic variables that are distinct from pure crystalline forms of this mineral. In general, impurities of iron oxides are only a small fraction of the total particle mass, and only slightly perturb the particle density that is determined primarily by the host mineral (Kandler et al., 2007; Scheuvens et al., 2011). Iron oxides present as a small impurity will travel farther than in their pure, crystalline form.

To our knowledge, measurements of mineral mixtures within individual aerosol particles are mostly anecdotal and provide only limited guidance about the combinations that need to be represented by a global model. In this study, the only combinations we represent explicitly are internal mixtures of iron oxides with another mineral, following Balkanski et al. (2007) and Scanza et al. (2015). Aggregates of other minerals will be represented implicitly as external mixtures, assuming that the removal rate of each mineral is approximately the same. Our construction of mixtures with iron oxides is described in Sect. 2.2.2. Previous treatments of aerosol mineral content have addressed the role of clays and feldspars as ice nuclei (e.g., Hoose et al., 2008; Atkinson et al., 2013), circumventing the consideration of iron oxide transport and mineral combinations. Our treatment of iron oxide impurities is possibly more speculative and subject to revision than the remainder of our method. Nonetheless, we address transport of this mineral because of its importance for shortwave absorption and deposition of bioavailable iron, even though we do not consider these applications in this study.

Our extensions to Claquin et al. (1999) are semi-empirical, but we evaluate our approach by comparison to a global compilation of measurements, as described in Part 2 of this article (Perlwitz et al., 2015) and in Pérez García-Pando et al. (2015).

\subsubsection{Observational constraints upon the emitted size distribution}

The transformation of the particle size distribution of the (undispersed) parent soil into the emitted size distribution is a complicated process that depends upon wind speed and the physical properties of the soil and land surface (Shao, 2001; Alfaro and Gomes, 2001; Grini et al., 2002; Marticorena, 2014). However, measurements suggest that for the smallest particles that are transported globally, the emitted size distribution is approximately independent of wind speed and soil properties (Gillette et al., 1972, 1974; Gillette, 1974; Kok, 2011a; Shao et al., 2011).

The theory of brittle fragmentation has been invoked to suggest that this invariance is robust, despite limited measurements of size-resolved emission (Kok, 2011b). In arid soils, mineral aggregates are typically most abundant at diameters between a few tens and a few hundred microns, according to measurements that minimally disturb the aggregates (cf. Fig. 4a of Shao, 2001). Brittle fragmentation theory proposes that energetic and repeated collisions, in this case between soil aggregates mobilized by saltation, will result in emitted aggregate diameters that are mostly smaller than a scale $\lambda$. According to this theory, the number concentration $\mathcal{N}$ of emitted particles varies inversely with the square of the diameter $D$ :

$\frac{d \mathcal{N}}{d \ln D} \propto \frac{1}{D^{2}} \exp \left[-\left(\frac{D}{\lambda}\right)^{3}\right]$ for $D>x_{0}$,

where the exponential imposes an upper bound on the emitted size range near diameter $\lambda$. The inverse-square dependence in Eq. (1) remains valid for diameters as small as $x_{0}$, the "indivisible" scale, where the material properties of the individual particles comprising the aggregates resist further disintegration.

For soil aggregates, Kok (2011b) proposes that there is a range of indivisible scales that is given by the distribution of soil particle diameters $D_{\mathrm{s}}$ after wet sieving, when aggregates have been dispersed and further disintegration is difficult. Then, if $p\left(D_{\mathrm{s}}\right) d D_{\mathrm{S}}$ is the distribution of wet-sieved diameters, the emitted number concentration is given by

$$
\frac{d \mathcal{N}}{d \ln D}=\frac{1}{c_{\mathcal{N}} D^{2}} \exp \left[-\left(\frac{D}{\lambda}\right)^{3}\right] \int_{0}^{D} p\left(D_{\mathrm{s}}\right) d D_{\mathrm{s}},
$$

where $c_{\mathcal{N}}$ is a normalization factor. The effect of the integral in Eq. (2) is to reduce the number concentration at smaller aggregate diameters compared to the inverse-square power law given by Eq. (1). This reduction occurs because emitted aggregates of diameter $D$ can be comprised only of particles with smaller indivisible scales (given by $D_{\mathrm{s}}$ ). Thus, the integral is the product of an inverse-square power-law dependence with the distribution of indivisible scales identified from the wet-sieved soil. 


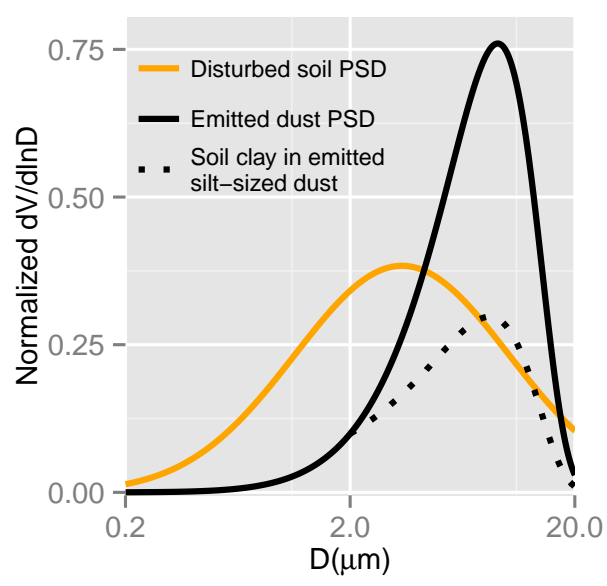

Figure 2. Size distribution of emitted dust (black line) derived from Eq. (2) with $\lambda=12 \mu \mathrm{m}$ (Kok, 2011b). The orange curve describes the arid dispersed soil used in the calculation of $U(D)$ in Eq. (2), and is represented by a monomodal log-normal distribution with a volume median diameter of $3.4 \mu \mathrm{m}$ and geometric SD of 3.0. Both curves are and normalized over the range $0-20 \mu \mathrm{m}$. The dotted line represents the contribution of dispersed soil clay particles to siltsized dust aggregates calculated with Eq. (2) and in this example contributes $45 \%$ of the emitted silt.

The emitted number concentration in Eq. (2) derived from brittle fragmentation theory is independent of the size distribution of the original, undispersed soil that is subject to wind erosion. The approximate upper bound $\lambda$ of emitted aggregates is estimated as $12 \pm 1 \mu \mathrm{m}$ by Kok (2011b), who performed a least-squares fit to the few available measurements of the emitted size distribution (Gillette et al., 1972, 1974; Gillette, 1974; Sow et al., 2009), after estimating $p\left(D_{\mathrm{S}}\right) d D_{\mathrm{s}}$ from measured size distributions of dispersed arid soils (d'Almeida and Schütz, 1983; Goldstein et al., 2005). This value is roughly ten percent of a typical aggregate diameter in the original soil and bounds the diameters of a majority of the particles that are dispersed globally downwind of their source.

Equation (2) predicts that the volume distribution of emitted aggregates will be shifted toward larger diameters, compared to the distribution of the wet-sieved soil, consistent with the measurements shown in Fig. 1. This is illustrated by Fig. 2, where the normalized distribution of emitted volume is shown as a black line, derived from the corresponding distribution of the fully dispersed soil shown in orange. In this example, the ratio of clay-sized mass to silt is 0.5 in the fully dispersed soil but only 0.05 after brittle fragmentation and emission of the undispersed soil. (The silt fraction here represents the sum of particle diameters up to $20 \mu \mathrm{m}$, below which we assume Eq. 2 is applicable.) That is, brittle fragmentation of aggregates during saltation preserves a greater fraction of mass at silt sizes compared to the breaking of aggregates during dispersion of the soil prior to measurement.
The dotted curve in Fig. 2 shows the contribution to silt emission from particles with indivisible scales at clay sizes in the fully dispersed soil. This contribution corresponds to about $45 \%$ of the emitted silt mass. In Sect. 2.2.1, we represent this empirically by augmenting the emitted silt fraction with clay-sized minerals identified in the wet-sieved soil. For example, we assume that phyllosilicates in the parent soil are also emitted at silt sizes even though these minerals are given by the MMT for the fully dispersed soil only at clay sizes (Claquin et al., 1999). We also use Eq. (2), the emitted size distribution derived by Kok (2011b), to specify the relative fraction of emitted clay and silt-sized particles. The prescription of an emitted size distribution that is independent of location is shared by studies of the global dust cycle that do not resolve mineral variations (e.g., Miller et al., 2006; Albani et al., 2014). This approach has also been used by Scanza et al. (2015) to account for the effect of brittle fragmentation upon the aerosol mineral composition.

The process of brittle fragmentation that leads to the emitted size distribution in Fig. 2 creates particles with diameters extending up to approximately $\lambda$. We assume that the specific range of validity is below $20 \mu \mathrm{m}$. At larger diameters, the emitted size distribution evolves through saltation and sandblasting with a complicated dependence upon wind speed and soil properties (Kok, 2011b). The range of emission by brittle fragmentation is mismatched with respect to the MMT whose silt size category extends to particle diameters up to $50 \mu \mathrm{m}$. To calculate the emitted fraction of clay and silt-sized particles over the size range corresponding to the MMT, we need to know the emitted size distribution between 20 and $50 \mu \mathrm{m}$. We obtain this from the normalized volume distribution in Fig. 3 (left panel), measured during the SAMUM campaign in Morocco (Kandler et al., 2009). (This figure is identical to Fig. 1, but is summed over all minerals and renormalized between 0 and $50 \mu \mathrm{m}$, the range of particle diameters corresponding to the MMT.) This figure provides the mass ratio corresponding to particle diameters between 2 to $20 \mu \mathrm{m}$ compared to diameters between 20 to $50 \mu \mathrm{m}$. Combining this ratio with the fraction of clay to silt particles with diameters up to $20 \mu \mathrm{m}$ provided by Eq. (2), equal to 0.05 , we calculate that clay-sized particles represent $1.3 \%$ of the total emitted mass for particle diameters up to $50 \mu \mathrm{m}$. By combining the size distributions of Kok (2011b) and Kandler et al. (2009) at diameters for which they are respectively valid, we arrive at the "corrected" size distribution of emission shown in the second panel from the left in Fig. 3.

By apportioning silt emission with measurements of the volume fraction after transport to a single location, we are making at least two approximations. First, we are assuming that the distribution at Tinfou is representative of other sources. The increase of the emitted silt fraction with increasing particle size (Fig. 3, second panel from left) is probably a robust consequence of the wind speed threshold for emission that decreases with diameter within this size range (Iversen and White, 1982). By neglecting variations in the emitted 


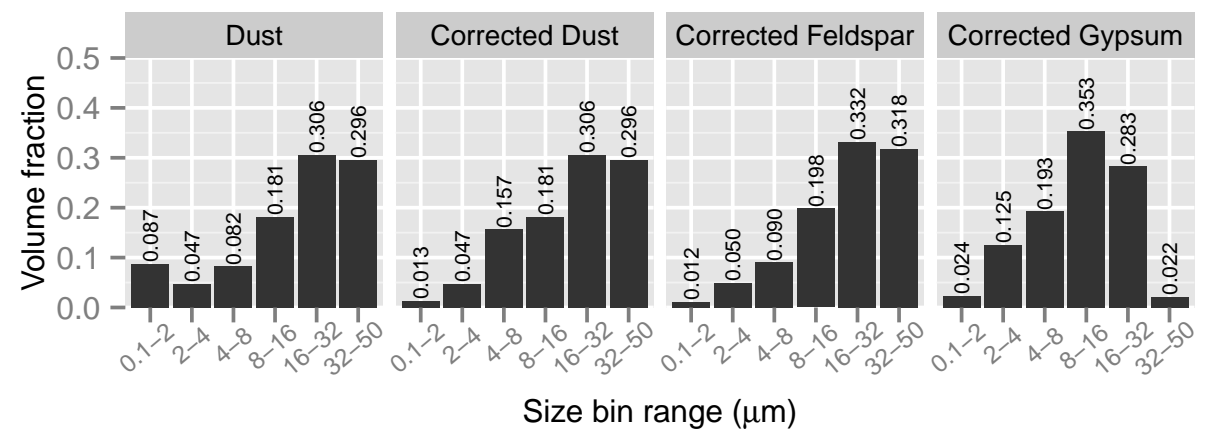

Figure 3. From left to right: Distribution of dust volume calculated by summing minerals in Fig. 1; same but with corrected ratio of clay to silt (up to $20 \mu \mathrm{m}$ ) using Eq. (2) (cf. Kok, 2011b); distribution of feldspar volume in Fig. 1, but with same correction based on Kok (2011b); same for gypsum. Each distribution is projected onto the ModelE2 transport bins (Table 4). A fifth "virtual" transport bin for diameters between 32 and $50 \mu \mathrm{m}$ is added so that the total diameter range corresponds to that of the MMT. Each distribution is normalized over the entire diameter range.

distribution that result from wind speed, we are assuming that the distribution depends primarily upon each mineral's intrinsic physical characteristics including its tendency to fragment. This neglect is less defensible for diameters between 20 and $50 \mu \mathrm{m}$ (compared to smaller particles for which Eq. (2) is a good approximation), but quantifying the validity of our assumption would require an emission model whose complexity is beyond the goals of the present study. Note that we prescribe an emitted distribution that is normalized over all sizes to remove the influence of the absolute value of emission upwind of Tinfou. Our second approximation is to neglect modification to the emitted size distribution by deposition during transport to Tinfou that preferentially removes larger particles by gravitational settling. We partially account for this removal by using measurements only during highdust events (Fig. 1, bottom row), which we assume correspond to recent emission. (We interpret the presence of large particles with diameters over $100 \mu \mathrm{m}$ as evidence that deposition has had little time to modify the emitted distribution.) We assess this approximation in Sect. 4.5.

\subsection{Calculating mineral fractions at emission}

\subsubsection{Algorithm}

Here, we describe our calculation of the emitted fraction of each mineral and its particle size distribution. We treat the dust particles as an external mixture of minerals, each corresponding to a separate prognostic variable. We create additional prognostic variables for mixtures of each mineral with iron oxides, where the latter is assumed to be a small fraction of the total particle mass. Calculation of iron oxide mixtures is described separately in Sect. 2.2.2.

We first derive the mineral composition of the fully dispersed soil following Claquin et al. (1999). Their MMT gives $f_{n}^{\mathrm{c}}(a)$ and $f_{n}^{\mathrm{s}}(a)$, the mass fraction of mineral $n$ in the clay ( 0 to $2 \mu \mathrm{m}$ ) and silt ( 2 to $50 \mu \mathrm{m}$ ) size categories, respectively, as a function of $\alpha$, the arid soil type, whose spatial distribution is provided by the DSMW (FAO, 2007) that is integrated into the Harmonized World Soil Database (HWSD FAO/IIASA/ISRIC/ISSCAS/JRC, 2012). (Table 1 describes the data sets used in this study.) For each value of soil type $\alpha$ (that implicitly varies with location), the mineral fractions given by the MMT sum to unity:

$\sum_{n}^{N} f_{n}^{\mathrm{c}}(\alpha)=1$ and $\sum_{n}^{N} f_{n}^{\mathrm{s}}(\alpha)=1$.

For Claquin et al. (1999), only calcite (or more generally, "carbonates") and quartz are present at all particle sizes. Phyllosilicates (illite, kaolinite, smectite) are present only at clay sizes, while feldspar, gypsum and hematite are restricted to silt sizes. Based upon measurements shown in Fig. 1, we assume that each mineral is present within all size categories, so that $N$, the total number of minerals, equals 8 for both clay and silt-sized particles (Table 2). The fraction of hematite provided by the MMT was originally derived using soil redness and assigned to the silt size category without reference to its measured size distribution. However, soil measurements show that iron oxides like hematite are present over a range of diameters as small as nanometers (Shi et al., 2012). Following Nickovic et al. (2012), we assume that hematite is present at both clay and silt sizes, assuming that the clay fraction is identical to the silt fraction provided by the MMT. We assume that the hematite fraction that is newly introduced at clay sizes occurs at the expense of the phyllosilicate fractions within the MMT. This is partly because iron oxides are a weathering product of phyllosilicates, but in practice this offset causes only a small reduction of the phyllosilicate fraction.

To calculate the mineral fractions of the dispersed soil at each location, we specify the fraction of each size category present, provided by the soil texture class $\beta$, whose spatial distribution is provided by the FAO/STATSGO soil texture (Table 1$)$. Let $s^{\mathrm{c}}(\beta)$ and $s^{\mathrm{s}}(\beta)$ be the mass fractions of clay 
Table 1. Data sets used in this study.

\begin{tabular}{|c|c|}
\hline Name and reference & Description \\
\hline $\begin{array}{l}\text { Mean Mineralogical Table (MMT) } \\
\text { (Claquin et al., 1999) }\end{array}$ & $\begin{array}{l}\text { Mineral fractions of clay and silt soil particles for } 25 \text { FAO arid soil } \\
\text { types. The MMT was expanded with } 3 \text { additional soil types (Yer- } \\
\text { mosols, Haplic Yermosols and Xerosols) whose mineral fractions } \\
\text { were extrapolated by Nickovic et al. (2012) from similar types. }\end{array}$ \\
\hline $\begin{array}{l}\text { Digital Soil Map of the World (DMSW) } \\
\text { (FAO, 2007; FAO/IIASA/ISRIC/ISSCAS/JRC, 2012) } \\
\text { www.fao.org/geonetwork/srv/en/metadata.show?id=14116 }\end{array}$ & $\begin{array}{l}\text { Geographical distribution of } 137 \text { soil types with a resolution of } 5^{\prime} \times \\
5^{\prime} \text { latitude by longitude. The MMT uses } 28 \text { arid soil types to assign } \\
\text { mineral fractions to the clay and silt-sized fractions of the soil. }\end{array}$ \\
\hline $\begin{array}{l}\text { Hybrid STATSGO/FAO } \\
\text { (FAO/IIASA/ISRIC/ISSCAS/JRC, 2012; NRCS Soil Survey } \\
\text { Staff, 2012) } \\
\text { www.ral.ucar.edu/research/land/technology/lsm.php }\end{array}$ & $\begin{array}{l}\text { Geographical distribution of soil texture classes (see Table } 3 \text { ). The } \\
\text { FAO global soil texture maps at } 5^{\prime} \times 5^{\prime} \text { latitude by longitude are } \\
\text { remapped onto a global } 30^{\prime \prime} \times 30^{\prime \prime} \text { latitude by longitude grid. Within } \\
\text { Contiguous United States (CONUS), the soil texture is replaced by } \\
\text { the } 30^{\prime \prime} \times 30^{\prime \prime} \text { STATSGO data. }\end{array}$ \\
\hline $\begin{array}{l}\text { Dust and mineral measurements at Tinfou, Morocco } \\
\text { (Kandler et al., 2009) }\end{array}$ & $\begin{array}{l}\text { Measurements of dust number and fractional mineral volume for } 10 \\
\text { size bins extending to } 250 \mu \mathrm{m} \text { at Tinfou, Morocco during the SAMUM } \\
\text { campaign in } 2006 \text {. }\end{array}$ \\
\hline
\end{tabular}

Table 2. Minerals represented in ModelE2. Closed circles (•) denote minerals identified in wet-sieved soils by Claquin et al. (1999). Stars $(\star)$ denote iron oxide extrapolated to clay sizes by Nickovic et al. (2012). Open circles (o) denote minerals restored to silt sizes that were disaggregrated by wet sieving. Triangles $(\triangleright)$ denote minerals introduced at clay sizes as suggested by measurements at Tinfou, Morocco, during SAMUM (Kandler et al., 2009).

\begin{tabular}{lccccc}
\hline \multirow{2}{*}{ Mineral } & \multicolumn{2}{c}{ Disturbed soil } & & \multicolumn{2}{c}{ Undisturbed soil and dust } \\
\cline { 2 - 3 } \cline { 5 - 6 } & Clay & Silt & & Clay & Silt \\
\hline Illite & $\bullet$ & & & $\bullet$ & $\circ$ \\
Kaolinite & $\bullet$ & & & $\bullet$ & $\circ$ \\
Smectite & $\bullet$ & & & $\bullet$ & $\circ$ \\
Quartz & $\bullet$ & $\bullet$ & & $\bullet$ & $\bullet$ \\
Carbonates & $\bullet$ & $\bullet$ & & $\bullet$ & $\bullet$ \\
Gypsum & & $\bullet$ & & $\triangleright$ & $\bullet$ \\
Feldspar & & $\bullet$ & & $\triangleright$ & $\bullet$ \\
Iron oxides & $\star$ & $\bullet$ & & $\star$ & $\bullet$ \\
\hline
\end{tabular}

and silt-sized particles provided by the soil texture triangle for each soil texture class $\beta$ (Table 3). The clay and silt-size fractions are normalized to sum to unity at each location:

$s^{\mathrm{c}}(\beta)+s^{\mathrm{s}}(\beta)=1$.

Thus, the soil mass fraction of each mineral in the clay and silt-size categories, $s_{n}^{\mathrm{c}}$ and $s_{n}^{\mathrm{s}}$, respectively, is given by

$s_{n}^{\mathrm{c}}(\alpha, \beta)=s^{\mathrm{c}}(\beta) f_{n}^{\mathrm{c}}(\alpha)$ and $s_{n}^{\mathrm{s}}(\alpha, \beta)=s^{\mathrm{s}}(\beta) f_{n}^{\mathrm{s}}(\alpha)$.

As a result of Eqs. (3) and (4), the soil mass fractions sum to unity over all sizes and minerals:

$\sum_{n}^{N}\left(s_{n}^{\mathrm{c}}+s_{n}^{\mathrm{s}}\right)=1$.
The soil mass fraction of each mineral varies regionally through its dependence upon the arid soil type $\alpha$ (through the MMT that gives the fractional mineral composition of each size category) and soil texture $\beta$ (that gives the local fractional abundance of each size category). For brevity, we will hereafter omit the dependence of $s_{n}^{\mathrm{c}}$ and $s_{n}^{\mathrm{s}}$ upon $\alpha$ and $\beta$ (and implicitly upon location).

We have derived Eq. (5), the mass fraction of each mineral within the dispersed soil, by applying the method of Claquin et al. (1999) with the extension of hematite to clay sizes following Nickovic et al. (2012). What remains is to specify the emitted fraction of each mineral within each size category.

Let $a^{\mathrm{c}}$ and $a^{\mathrm{s}}$ be the mass fractions of emitted clay and silt-sized aerosols, respectively, that at each location satisfy

$a^{\mathrm{c}}+a^{\mathrm{s}}=1$.

(The symbols " $a$ " and " $s$ " are chosen to signify the aerosol and soil, respectively.) We further decompose each aerosol mass fraction into contributions from the $N$ minerals. Let $a_{n}^{\mathrm{c}}$ and $a_{n}^{\mathrm{s}}$ represent the contribution of mineral $n$ to the mass fraction of emitted clay and silt-sized particles, respectively:

$a^{\mathrm{c}}=\sum_{n}^{N} a_{n}^{\mathrm{c}}$ and $a^{\mathrm{s}}=\sum_{n}^{N} a_{n}^{\mathrm{s}}$,

that because of Eq. (7) satisfy

$\sum_{n}^{N}\left(a_{n}^{\mathrm{c}}+a_{n}^{\mathrm{s}}\right)=1$.

That is, the sum of the aerosol mineral fractions over all sizes and minerals equals unity.

We prescribe the mass fraction of the emitted clay-sized particles using brittle fragmentation theory, as described in 
Table 3. Soil texture classes with sand, silt, and clay percentages, and clay $\left(s^{\mathrm{c}}\right)$ and silt $\left(s^{\mathrm{s}}\right)$ mass fractions (relative to clay plus silt) in the Hybrid STATSGO/FAO soil texture database that are used for the derivation of the mineral fractions.

\begin{tabular}{llccccc}
\hline Class & Texture & Sand $(\%)$ & Silt $(\%)$ & Clay $(\%)$ & $s^{\mathrm{c}}$ & $s^{\mathrm{s}}$ \\
\hline 1 & Sand & 92 & 5 & 3 & 0.38 & 0.62 \\
2 & Loamy sand & 82 & 12 & 6 & 0.33 & 0.67 \\
3 & Sandy loam & 58 & 32 & 10 & 0.24 & 0.76 \\
4 & Silt loam & 17 & 70 & 13 & 0.16 & 0.84 \\
5 & Silt & 10 & 85 & 5 & 0.06 & 0.94 \\
6 & Loam & 43 & 39 & 18 & 0.32 & 0.68 \\
7 & Sandy clay loam & 58 & 15 & 27 & 0.64 & 0.36 \\
8 & Silty clay loam & 10 & 56 & 34 & 0.38 & 0.62 \\
9 & Clay loam & 32 & 34 & 34 & 0.5 & 0.5 \\
10 & Sandy clay & 52 & 6 & 42 & 0.88 & 0.12 \\
11 & Silty clay & 6 & 47 & 47 & 0.5 & 0.5 \\
12 & Clay & 22 & 20 & 58 & 0.74 & 0.26 \\
\hline
\end{tabular}

Sect. 2.1.2 and shown in Fig. 3 (second panel from the left):

$a^{\mathrm{c}}=0.013$.

We assume that $a^{\mathrm{c}}$ is independent of location, based upon Kok (2011b), who argues that the black curve in Fig. 2 is a good approximation to measurements of the emitted size fraction for a variety of soils and wind conditions. As a consequence of Eqs. (5) and (10), the emission of clay-sized mineral $n$ (excluding feldspar and gypsum) is

$a_{n}^{\mathrm{c}}(\alpha)=a^{\mathrm{c}} f_{n}^{\mathrm{c}}(\alpha) \quad$ where $a^{\mathrm{c}}=0.013$

Note that for emission at clay sizes, the proportion of minerals is identical to that of the fully dispersed soil and given by the MMT.

Because of Eq. (7), the emitted silt fraction $a^{\mathrm{s}}$ is implicitly determined:

$a^{\mathrm{s}}=1-a^{\mathrm{c}}=0.987$.

As noted above, the assumption of an emitted size distribution that is spatially uniform is shared by many models, including those with uniform or else varying mineral content (e.g., Miller et al., 2006; Scanza et al., 2015).

We also assume that the emitted mass fraction of each mineral $n$ at silt sizes $\left(a_{n}^{\mathrm{s}}\right)$ consists of two contributions from the wet-sieved soil. The emitted fraction combines soil mass at silt sizes along with clay particles whose aggregates were broken during wet sieving. This is expressed by Eq. (2), but we represent reaggregation more simply by augmenting emission at silt sizes in proportion to the fractional abundance of clay particles in the fully dispersed soil $\left(s_{n}^{\mathrm{c}}\right)$ :

$a_{n}^{\mathrm{s}}=\eta\left(\gamma_{n} s_{n}^{\mathrm{c}}+s_{n}^{\mathrm{s}}\right)$.

Here, $\gamma_{n}$ is a coefficient of proportionality that controls the magnitude of reaggregation and augmentation of the emitted silt fraction for mineral $n$. For simplicity, we assume that $\gamma_{n}$ is identical for all reaggregated minerals, except for feldspar and gypsum, which must be treated separately as described below. The remaining exception is quartz, whose abundance at large diameters in Fig. 1 suggests that it experiences minimal dispersion, which we represent by setting $\gamma_{n}=0$. The parameter $\eta$ is calculated at each location to satisfy Eq. (12).

As a consequence of Eqs. (5) and (13), the emission of mineral $n$ at silt sizes is

$a_{n}^{\mathrm{s}}(\alpha, \beta)=\eta(\alpha, \beta)\left[\gamma_{n} s^{\mathrm{c}}(\beta) f_{n}^{\mathrm{c}}(\alpha)+s^{\mathrm{s}}(\beta) f_{n}^{\mathrm{s}}(\alpha)\right]$,

noting that $\gamma_{n} \equiv \gamma$, a constant that is identical for all minerals, except for quartz, for which $\gamma_{n} \equiv 0$. We have temporarily noted the dependence of the silt fraction $a^{\mathrm{s}}$ upon the local soil type $\alpha$ and texture $\beta$.

Equation (14) extends clay-sized minerals like phyllosilicates into the silt-size range, consistent with measurements by Kandler et al. (2009), illustrated in Fig. 1. This extension increases in proportion to the clay fraction of the fully dispersed soil, a heuristic representation of Eq. (2).

Because the total fractional silt emission is assumed to be fixed according to Eq. (12), $\gamma$ has the effect of reducing the fractional emission of minerals like quartz that are predominantly silt-sized in the dispersed soil. We show below and in Part 2 (Perlwitz et al., 2015) that this reduction leads to improved agreement with observations. This fractional reduction of emitted minerals like quartz whose size is largely unmodified by wet sieving is a consequence of the reintroduction of aggregates that were destroyed by dispersion but would have been emitted from the original, undispersed soil following brittle fragmentation.

Feldspar and gypsum are observed as aerosols at both clay and silt sizes (Fig. 1). Because of the absence of each mineral at clay sizes within the MMT (Claquin et al., 1999), we cannot specify the emitted clay fraction using Eq. (11). Instead, we assume that the emitted silt mass of each mineral $\left(a_{n}^{\mathrm{s}}\right)$ is closely related to its soil mass fraction $\left(s_{n}^{\mathrm{s}}\right)$. Then, we calculate the emitted clay mass using its ratio $\left(\psi_{n}\right)$ with respect to 


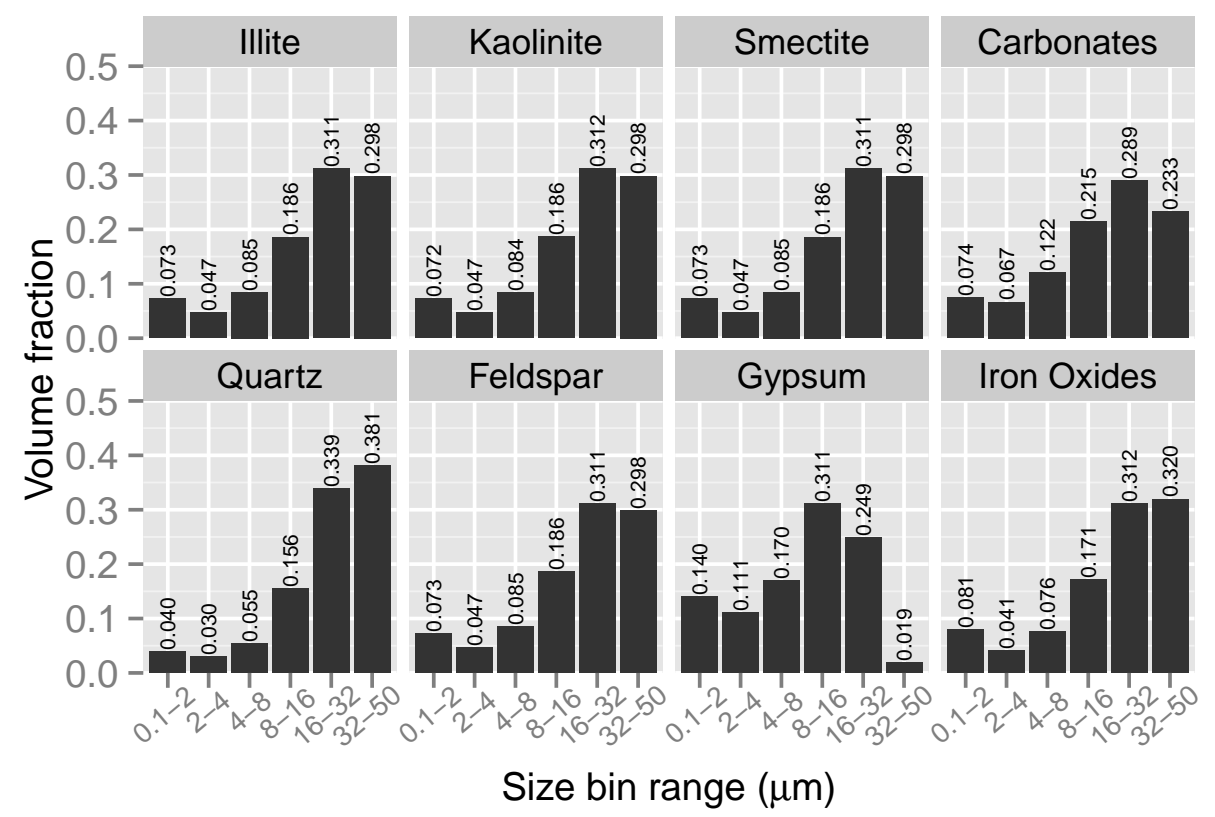

Figure 4. Fractional distribution of volume within the ModelE2 size bins for the minerals in Table 2, calculated by interpolating the distributions in Fig. 1. A fifth "virtual" transport bin for diameters between 32 and $50 \mu \mathrm{m}$ is added so that the total diameter range corresponds to that of the MMT. The distribution of each mineral is normalized separately over the entire diameter range.

the emitted silt mass:

$a_{n}^{\mathrm{c}}=\psi_{n} a_{n}^{\mathrm{s}}$

where

$a_{n}^{\mathrm{s}}=\eta(\alpha, b) s^{\mathrm{s}}(b) f_{n}^{\mathrm{s}}(\alpha)$,

and $n$ corresponds to feldspar and gypsum. The ratio $\psi_{n}$ is given by the measured volume distribution after adjusting for modification of the emitted size distribution at small diameters during transport to Tinfou. This adjustment is shown in the right two panels of Fig. 3, and its derivation is identical to the calculation of $a^{\mathrm{c}}=0.013$ (Fig. 3, second panel), except that the latter uses the measured size distribution summed over all minerals (Fig. 3, left panel), while the derivation of $\psi_{n}$ is based upon the individual size distribution of either feldspar or gypsum (Fig. 1). We proportionally reduce the soil fractions of illite, smectite and kaolinite at clay sizes to compensate for the reintroduction of emitted feldspar and gypsum at this size. (This is an alternative to reducing all the soil mineral fractions at clay sizes. We justify this approximation as a result of the predominance of phyllosilicates at this size according to the MMT.)

The emitted silt particles have diameters ranging between 2 and $50 \mu \mathrm{m}$ (consistent with the MMT). We distribute each mineral's silt particles over the size categories transported by ModelE2 (Table 4). (Clay-sized particles are transported in a single bin by ModelE2, so distribution within this size range is unnecessary.) We introduce an additional model size category between 32 and $50 \mu \mathrm{m}$ that is not transported so
Table 4. Size categories for dust transported in ModelE2. $k$-index is the subscript denoting the particle size of the soil and emitted mass fractions. Note that the sixth size category (comprised of the largest particles) is not transported, and exists solely to match the diameter range corresponding to the MMT.

\begin{tabular}{lc}
\hline Diameter $(\mu \mathrm{m})$ & $k$-index \\
\hline Clay & \\
$0.1-2$ & 1 \\
\hline Silt & \\
$2-4$ & 2 \\
$4-8$ & 3 \\
$8-16$ & 4 \\
$16-32$ & 5 \\
$32-50$ & 6 \\
\hline
\end{tabular}

that the total silt size ranges within the model and MMT are identical. Let $a_{n, k}^{\mathrm{s}}$ be the emitted mass fraction of mineral $n$ within size category $k$. To distribute the silt mass, we use the normalized mass distribution of each mineral derived from measurements during SAMUM (Kandler et al., 2009), shown in Fig. 4. We define $m_{n, k}^{\mathrm{s}}$ as the mass fraction within size bin $k$ that is normalized for each mineral $n$ over the MMT silt range (between 2 and $50 \mu \mathrm{m}$ ) so that

$\sum_{\substack{\text { all silt } \\ \text { size bins }}} m_{n, k}^{\mathrm{s}}=1$ for each mineral $n$. 
Table 5. List of symbols used to represent mass fractions of soil and emitted minerals (Sect. 2.2.1).

\begin{tabular}{ll}
\hline$\alpha$ & Soil type \\
$\beta$ & Soil texture \\
$s^{\mathrm{c}}$ & Mass fraction of clay-sized soil particles relative to total clay and silt (Table 3) \\
$s^{\mathrm{s}}$ & Mass fraction of silt-sized soil particles relative to total clay and silt (Table 3) \\
$f_{n}^{\mathrm{c}}$ & Mass fraction of soil mineral $n$ (relative to clay-sized minerals) \\
$f_{n}^{n}$ & Mass fraction of soil mineral $n$ (relative to silt-sized minerals) \\
$s_{n}^{\mathrm{c}}$ & Mass fraction of soil mineral $n$ at clay sizes \\
$s_{n}^{\mathrm{s}}$ & Mass fraction of soil mineral $n$ at silt sizes \\
$a^{\mathrm{c}}$ & Mass fraction of emitted clay-sized dust \\
$a^{\mathrm{s}}$ & Mass fraction of emitted silt-sized dust \\
$a_{n}^{\mathrm{c}}$ & Mass fraction of emitted mineral $n$ at clay sizes \\
$a_{n}^{\mathrm{s}}$ & Mass fraction of emitted mineral $n$ at silt sizes \\
$a_{n, k}^{\mathrm{s}}$ & Mass fraction of emitted mineral $n$ within the silt size category $k$ (for $k=2, \ldots 6$ ) \\
$\gamma$ & Parameter controlling reaggregation of emitted silt particles from wet-sieved clay \\
& particles \\
$\psi_{n}$ & Parameter related to reaggregation \\
& Ratio of the emitted clay-sized mass fraction to the emitted silt fraction for feldspar \\
$m_{n, k}$ & and gypsum \\
\hline
\end{tabular}

Table 6. List of symbols used to represent mixtures of iron oxide and other minerals (Sect. 2.2.2).

\begin{tabular}{ll}
\hline$a_{n, k}$ & Mass fraction of mineral $n$ in size class $k\left(a_{n, 1}=a_{n}^{\mathrm{c}}, a_{n, k}=a_{n, k}^{\mathrm{s}}\right.$ for $\left.k=2, \ldots 6\right)$ \\
$a_{n, k}^{\text {pure }}$ & Mass fraction of uncombined mineral $n$ in size class $k$ (excluding iron oxide) \\
$a_{n, k}^{\text {mix }}$ & Mass fraction of mineral $n$ with mixed with iron oxide \\
$a_{\mathrm{Fe}, k}$ & Mass fraction of iron oxide in size class $k$ \\
$a_{\mathrm{Fe}, k}^{\mathrm{pure}}$ & Mass fraction of pure crystalline iron oxide $k$ \\
$a_{\mathrm{Fe}, k}^{\mathrm{mix}}$ & Mass fraction of iron oxide mixed with other minerals \\
$a_{\mathrm{Fe} \mid n, k}^{\mathrm{mix}}$ & Mass fraction of iron oxide mixed with mineral $n$ \\
$\epsilon$ & Fraction of iron oxide not available for mixing \\
$\epsilon_{0}$ & Coefficient of proportionality between $a_{\mathrm{Fe}, k}$ and $\epsilon$ \\
$R$ & Fraction of mixed particle mass contributed by iron oxide \\
$\bar{a}_{k}$ & Mass fraction of all non-iron oxide minerals in size class $k$ \\
\hline
\end{tabular}

Then, the emitted mineral fraction within each silt size bin $k$ is

$a_{n, k}^{\mathrm{s}}=a_{n}^{\mathrm{s}} m_{n, k}^{\mathrm{s}}$.

(The $m_{n, k}^{\mathrm{s}}$ are proportional to the values shown in Fig. 4, but differ slightly because the former are normalized only over the range of silt sizes. In contrast, the values in Fig. 4 include the clay-size bin in their normalization.)

Finally, we renormalize the mass fractions $a_{n}^{\mathrm{c}}$ and $a_{n, k}^{\mathrm{s}}$ so that their sum over all minerals and sizes is unity for diameters up to $32 \mu \mathrm{m}$. (Silt particles with diameters between 32 and $50 \mu \mathrm{m}$ are not transported by the model.) This renormalization has the effect of reducing the fraction of quartz compared to the MMT. This is because a greater mass fraction of quartz is measured at diameters above $32 \mu \mathrm{m}$, compared to other minerals, according to Fig. 4. For example, quartz has $38 \%$ of its mass between 32 and $50 \mu \mathrm{m}$, a significantly larger amount than that of carbonates $(23 \%)$, feldspar $(30 \%)$ and particularly gypsum ( $2 \%)$. The shift of quartz aerosols toward larger diameters compared to other minerals results from the larger characteristic particle size of quartz in the parent soil. Thus, the fractional emission of quartz at silt sizes is reduced by two effects compared to the fraction indicated by the MMT: first, the reconstruction of emitted aggregates at silt sizes from wet-sieved clay-sized particles, and second, the limited size range of our transport model. The second effect is ultimately the result of a disproportionate mass of quartz at diameters that are too large to travel far from their source.

Our model generally resembles that of Scanza et al. (2015) although there are differences that illuminate the physical processes represented by both studies. Our calculation of the emitted size distribution Eq. (14) accounts for local soil texture, reconstructing more silt-sized aggregates where $s^{\mathrm{c}}$, the fraction of clay-sized particles, is particularly large. In contrast, Scanza et al. (2015) assume a globally invariant 
size distribution of the wet-sieved soil. In addition, the latter study reconstructs the aggregates of all minerals identically, including quartz, whose reaggregation we neglect due to its presumed mechanical stability and resistance to disintegration during both brittle fragmentation and wet sieving. The omission of quartz reaggregation reduces the relative fraction of quartz at silt sizes in our model. Finally, we use the measurements of Kandler et al. (2009) to truncate the mineral fractions of emitted silt derived from the MMT (representing diameters up to $50 \mu \mathrm{m}$ ) to fit the transport categories of our model (that extend only to $32 \mu \mathrm{m}$ ). In contrast, Scanza et al. (2015) apply the entire emitted fraction derived from the MMT to their model transport categories that extend only to $10 \mu \mathrm{m}$. This contrast reduces the relative fraction of quartz transported at silt sizes in our model for two reasons. First, our model emits a larger fraction of quartz at diameters above $10 \mu \mathrm{m}$, where the particle lifetime is shorter. Second, our model entirely excludes the fraction of quartz emitted at diameters above $32 \mu \mathrm{m}$ (where its measured volume fraction is disproportionately large according to Fig. 4).

\subsubsection{Transport of iron oxides as internal mixtures}

In our model, iron oxides can travel either in pure crystalline form or as an internal mixture with other minerals. (Combinations of the other minerals excluding iron oxides are treated as external mixtures.) Our apportionment of iron oxides combines the two limiting cases considered by Scanza et al. (2015). In that study, iron oxide is treated as either a pure component within an external mixture, or else an internal mixture with phyllosilicates and the other minerals. We refer to the iron oxide within an internal mixture as an "accretion". (We avoid referring this mixture as an aggregate to avoid confusion with the more general class of aggregated minerals that are subject to brittle fragmentation.)

At each location, Eqs. (11) and (14), along with (15) and (16), give us $a_{n, k}^{\mathrm{c}}$ and $a_{n, k}^{\mathrm{s}}$, including the mass fraction of emitted iron oxide. To create mixtures with other minerals, we specify the hematite fraction available for mixing along with its mass fraction in each particle. (We describe mixtures in terms of "iron oxides" rather than hematite, whose fraction is provided by the MMT, because our mixing method applies to other highly weathered iron minerals like goethite that are frequently found in aggregation; Lafon et al. 2006; Kandler et al. 2007; Journet et al. 2014.)

To simplify notation, we drop the superscripts in Eqs. (11), (14), (15) and (16) that distinguish between clay and siltsized particles, and denote particle size solely through the $k$ index of $a_{n, k}$. For the GISS ModelE2, $k=1$ corresponds to the clay-sized fraction, while transported silt sizes correspond to $k$ equal to 2 through 5 (Table 4).

We first distinguish between each mineral in its pure and mixed state:

$a_{n, k}=a_{n, k}^{\text {pure }}+a_{n, k}^{\operatorname{mix}}$.
For the particular case of iron oxides, we replace the mineral index $n$ with $\mathrm{Fe}$, so that $a_{\mathrm{Fe}, k}$ denotes the emitted mass fraction of iron oxide in size category $k$. Then, analogous to Eq. (19), iron oxides can be decomposed into pure crystals and impurities mixed with other minerals:

$a_{\mathrm{Fe}, k}=a_{\mathrm{Fe}, k}^{\text {pure }}+a_{\mathrm{Fe}, k}^{\operatorname{mix}}$.

We further distinguish the mixture of iron oxide among the remaining minerals (each denoted by the subscript $n$ ) as $a_{\mathrm{Fe} \mid n, k}^{\operatorname{mix}}$, so that the total iron oxide within mixtures is the sum over $n$ :

$a_{\mathrm{Fe}, k}^{\operatorname{mix}}=\sum_{n \neq \text { iron oxide }} a_{\mathrm{Fe} \mid n, k}^{\operatorname{mix}}$.

We determine $a_{\mathrm{Fe} \mid n, k}^{\operatorname{mix}}$ by first specifying the fraction of emitted iron oxide available for mixing. Define $\epsilon$ as the fraction of iron oxide emitted as pure crystals:

$a_{\mathrm{Fe}, k}^{\mathrm{pure}}=\epsilon a_{\mathrm{Fe}, k}$.

Micrometer-sized crystalline iron oxide aggregates are typically observed in highly weathered soils that are rich in iron oxides (Chesworth, 2008). Therefore, we assume that the amount of crystalline iron oxides not attached as small impurities to other minerals is proportional to the total iron oxide content of the soil, so that $\epsilon$ is proportional to the total iron oxide:

$\epsilon=\epsilon_{0} a_{\mathrm{Fe}, k}$.

Then,

$a_{\mathrm{Fe}, k}^{\mathrm{pure}}=\epsilon_{0} a_{\mathrm{Fe}, k}^{2}$,

and using Eq. (20),

$a_{\mathrm{Fe}, k}^{\operatorname{mix}}=(1-\epsilon) a_{\mathrm{Fe}, k}=\left(1-\epsilon_{0} a_{\mathrm{Fe}, k}\right) a_{\mathrm{Fe}, k}$.

Equation (23) expresses our assumption that the fraction of pure crystalline iron oxide increases where the total iron oxide fraction is large, a heuristic attempt to account for the weathering that creates iron oxides in the soil. As a soil weathers, more of the primary and secondary Fe-bearing minerals decompose and the iron within the mineral lattices is converted to iron oxides in the soil (McFadden and Hendricks, 1985; Shi et al., 2012). In absence of quantitative observational constraints, we simply set $\epsilon_{0}=1$. In the future, $\epsilon_{0}$ could be prescribed differently or even be a function of other soil properties.

We next assume that iron oxide is mixed with the other minerals in proportion $R$ to the total particle mass:

$a_{\mathrm{Fe} \mid n, k}^{\operatorname{mix}}=R\left(a_{n, k}^{\operatorname{mix}}+a_{\mathrm{Fe} \mid n, k}^{\operatorname{mix}}\right)$.

We assume that $R$ is a small number so that the iron oxides only slightly perturb the density of the mixture. We set $R$ 
equal to 0.05 , but are aware of only a few measurements that would guide a more precise choice of this parameter. In Sect. 4.4, we calculate that the contribution of aggregated iron oxide to the global dust load is just under $2 \%$, comparable with the fraction inferred or assumed by other studies (e.g., Sokolik and Toon, 1999; Koven and Fung, 2006; Balkanski et al., 2007; Wagner et al., 2012; Moosmüller et al., 2012). In that section, we suggest that this global fraction is insensitive to our choice of $R$.

Finally, we assume that the iron oxide available for mixing is distributed among the other minerals in proportion to their mass fraction:

$a_{\mathrm{Fe} \mid n, k}^{\operatorname{mix}} \propto \frac{a_{n, k}}{\bar{a}_{k}}$,

where $\bar{a}_{k}$ is the mass fraction for each size category summed over all minerals except for iron oxide.

$\bar{a}_{k}=\sum_{n \neq \text { iron oxide }} a_{n, k}$

Equation (27) is a reasonable first assumption, although future efforts might construct mixtures by considering whether iron oxides are more likely to be created by weathering of specific minerals. For example, iron oxides and clay minerals are formed during chemical weathering of parent minerals and are in intimate physical association with each other (Reid et al., 2003; Shi et al., 2012).

As a result of Eqs. (25) and (27),

$a_{\mathrm{Fe} \mid n, k}^{\operatorname{mix}}=\left(1-a_{\mathrm{Fe}, k}\right) a_{\mathrm{Fe}, k} \frac{a_{n, k}}{\bar{a}_{k}}$.

In Appendix A, we use these assumptions to derive the emitted mass fraction of iron oxide mixed with mineral $n$ :

$a_{n, k}^{\operatorname{mix}}+a_{\mathrm{Fe} \mid n, k}^{\operatorname{mix}}=\min \left[\frac{\left(1-a_{\mathrm{Fe}, k}\right) a_{\mathrm{Fe}, k}}{R} \frac{a_{n, k}}{\bar{a}_{k}}, \frac{a_{n, k}}{1-R}\right]$.

As shown in Appendix A, the second term within the minimum results from the possibility that for small enough mass fractions of accreted iron oxide within each particle $(R \ll 1)$, there will be insufficient amounts of mineral $n$ available for combination with the amount of iron oxide specified by Eq. (25).

The mass fraction of pure, crystalline iron oxide is given by

$a_{\mathrm{Fe}, k}^{\text {pure }}=a_{\mathrm{Fe}, k}-\min \left[\left(1-a_{\mathrm{Fe}, k}\right) a_{\mathrm{Fe}, k}, \frac{R}{1-R} \bar{a}_{k}\right]$,

while the mass fraction of pure mineral $n$ is given by

$a_{n, k}^{\text {pure }}=a_{n, k}-\left(\frac{1-R}{R}\right) a_{\mathrm{Fe} \mid n, k}^{\operatorname{mix}}$.

According to Eq. (26), iron oxides are accreted with host minerals within the same size category $k$. This follows from our interpretation of $a_{\mathrm{Fe} \mid n, k}^{\mathrm{mix}}$ as the mass fraction of iron oxides within these particle combinations, whose size category $k$ indicates the diameter of the combined particle. This diameter mainly reflects the contribution of the host mineral $n$, given our assumption that the fractional contribution $R$ of iron oxide mass to the combined particle is small. The accreted fraction $a_{\mathrm{Fe} \mid n, k}^{\mathrm{mix}}$ represents the small crystals of iron oxides attached to the host mineral as seen in single-particle images (Scheuvens and Kandler, 2014). We emphasize that these iron oxides available for mixing are not particles themselves with diameters within the size category $k$. In contrast, the fraction of pure, crystalline iron oxides $\left(a_{n, k}^{\text {pure }}\right)$ that does not combine with other minerals has a particle diameter within size category $k$.

Our modeling assumptions leading to Eq. (30) should be evaluated with more measurements of the size distribution and mixing state of iron oxides in the soil.

\subsection{Soil dust tracers in ModelE2}

Our model of the emitted mineral fractions has been incorporated into the CMIP5 version of the NASA GISS Earth System ModelE2 (Schmidt et al., 2014) that has horizontal resolution of $2^{\circ}$ latitude by $2.5^{\circ}$ longitude and 40 vertical layers up to $0.1 \mathrm{hPa}$. Here, we summarize the dust aerosol module that is largely unchanged since its description in Miller et al. (2006). The values $a_{n, k}$ give the fractional emission of each mineral within each transported size category. What remains is to calculate the total emission at each location.

Emission occurs when the surface wind speed $w$ exceeds a threshold $w_{\mathrm{T}}$. Subgrid variations of wind speed are introduced using a probability distribution $s(w) \mathrm{d} w$ (Cakmur et al., 2004), so that the total emission $E$ at each location is

$E=C S Z \int_{w_{T}}^{\infty} w^{2}\left(w-w_{\mathrm{T}}\right) s(w) \mathrm{d} w$,

where $S$ identifies regions of abundant easily erodible soil particles, and is an updated version of the source map derived by Ginoux et al. (2001). The parameter $Z$ identifies regions of sparse vegetation, where the soil particles are exposed to the force of the wind, and is derived from the climatological annual cycle of surface roughness retrieved from a microwave scatterometer (Prigent et al., 2005). The threshold wind speed $w_{\mathrm{T}}$ in Eq. (33) increases with soil wetness $q$, following Shao et al. (1996):

$w_{\mathrm{T}}=w_{\mathrm{T}, 0} \exp (0.7 q)$,

where $w_{\mathrm{T}, 0}=8 \mathrm{~m} \mathrm{~s}^{-1}$ is the emission threshold of the $10 \mathrm{~m}$ surface wind speed for completely dry soil. The parameter $C$ controls the magnitude of the global dust cycle. For all experiments, the global, annual emission is $2224 \pm 100 \mathrm{Tg}$ for particle diameters up to $32 \mu \mathrm{m}$ (Table 7). In this and the companion article (Perlwitz et al., 2015), our comparison to 
Table 7. Globally averaged dust emission, load and lifetime. The number in parentheses is 1 standard deviation (SD) of interannual variability.

\begin{tabular}{|c|c|c|c|c|}
\hline & \multicolumn{2}{|c|}{ SMF } & \multicolumn{2}{|c|}{ AMF } \\
\hline $\begin{array}{l}\text { Clay }(0-2 \mu \mathrm{m}) \\
\text { Silt }(2-16 \mu \mathrm{m}) \\
\text { Total }(<16 \mu \mathrm{m}) \\
\text { Silt }(16-32 \mu \mathrm{m})\end{array}$ & $\begin{array}{r}920 \\
657 \\
1577 \\
647\end{array}$ & $( \pm 70)$ & $\begin{array}{r}44 \\
1049 \\
1094 \\
1131\end{array}$ & $( \pm 49)$ \\
\hline Total $(<32 \mu \mathrm{m})$ & 2224 & $( \pm 100)$ & 2224 & $( \pm 100)$ \\
\hline $\begin{array}{l}\text { Load }(\mathrm{Tg}) \\
\text { Clay }(0-2 \mu \mathrm{m}) \\
\text { Silt }(2-16 \mu \mathrm{m}) \\
\text { Total }(<16 \mu \mathrm{m}) \\
\text { Silt }(16-32 \mu \mathrm{m})\end{array}$ & $\begin{array}{r}14.60 \\
4.66 \\
19.26 \\
0.46\end{array}$ & $( \pm 0.73)$ & $\begin{array}{l}0.71 \\
7.31 \\
8.02 \\
0.81\end{array}$ & $( \pm 0.29)$ \\
\hline Total $(<32 \mu \mathrm{m})$ & 19.72 & $( \pm 0.74)$ & 8.83 & $( \pm 0.31)$ \\
\hline $\begin{array}{l}\text { Lifetime }(<16 \mu \mathrm{m})(\mathrm{d}) \\
\text { Emission } \\
\text { Wet deposition } \\
\text { Gravitational settling } \\
\text { Turbulent deposition }\end{array}$ & $\begin{array}{r}4.45 \\
8.35 \\
19.05 \\
20.44\end{array}$ & & $\begin{array}{r}2.68 \\
8.87 \\
5.07 \\
16.35\end{array}$ & \\
\hline $\begin{array}{l}\text { Lifetime }(<32 \mu \mathrm{m})(\mathrm{d}) \\
\text { Emission } \\
\text { Wet deposition } \\
\text { Gravitational settling } \\
\text { Turbulent deposition }\end{array}$ & $\begin{array}{r}3.24 \\
8.41 \\
7.40 \\
19.23\end{array}$ & & $\begin{array}{r}1.45 \\
9.08 \\
1.98 \\
14.01\end{array}$ & \\
\hline
\end{tabular}

measurements is based upon mineral fractions that are independent of the value of $C$. Consequently, the global emission is presented for illustrative purpose only, and we make no effort to adjust $C$ to match any measurements of the dust cycle (cf. Cakmur et al., 2006).

Emission of each mineral is the total emission $E$ from Eq. (33) multiplied by the fractions $a_{n, k}$ (and their decomposition into pure and mixed states) derived above.

Each mineral is advected using the Quadratic Upstream Scheme (Prather, 1986), which keeps track of nine subgridscale moments as well as the tracer mean within each grid box, increasing the effective resolution for transport.

Removal of the mineral tracers from the atmosphere takes place by wet and dry deposition. Dry deposition includes gravitational settling and turbulent deposition in the surface layer. Settling speeds are proportional to mineral density (Tegen and Fung, 1994), whose values are given in Table 8. Note that the minerals have nearly identical densities, except for iron oxides whose density is nearly twice the value of the other minerals. Turbulent mixing near the surface is calculated using the same exchange coefficient as humidity. The calculations of the deposition velocities in the surface layer are based on a "resistance in series" scheme (Wesely and Hicks, 1977; Koch et al., 1999).
Table 8. Mineral densities in $10^{3} \mathrm{~kg} \mathrm{~m}^{-3}$. The densities of illite and smectite are an average of their individual values, since they are often found interleaved. Feldspar density is taken from plagioclase. The iron oxide density is an average of hematite and goethite. The densities were taken from http://www.mindat.org and http://www. webmineral.com.

\begin{tabular}{lc}
\hline Mineral & Density \\
\hline Illite & 2.57 \\
Kaolinite & 2.63 \\
Smectite & 2.57 \\
Calcite & 2.71 \\
Quartz & 2.67 \\
Feldspar & 2.68 \\
Iron oxides & 4.77 \\
\hline
\end{tabular}

Wet deposition occurs through scavenging both within clouds and below where there is precipitating condensate, while aerosols are restored by re-evaporation of cloud droplets and precipitate (Bauer and Koch, 2005; Schmidt et al., 2006). This represents a broader range of scavenging processes than the single scavenging coefficient used by Miller et al. (2006), and is now consistent with the treatment of other aerosol species. Within clouds, dust aerosols are scavenged where they nucleate precipitating cloud droplets. Nucleation depends upon particle solubility, which is assumed to be $50 \%$ for all minerals throughout the particle lifetime. In a future study, we will represent particle aging, where solubility evolves along the aerosol trajectory as a result of physical and chemical transformations that depend upon mineral composition (cf. Baker et al., 2014).

We also defer calculation of dust radiative forcing and its dependence upon spatial variations in the aerosol mineral composition. This eliminates feedbacks between dust radiative forcing and emission resulting, for example, from the perturbed surface wind speed or precipitation (e.g., Miller et al., 2014).

\section{Model simulations}

We evaluate our new approach in comparison to a control or "baseline" simulation that assumes the emitted mineral fractions are identical to those of the wet-sieved soil. We conduct a set of simulations with the NASA GISS ModelE2 covering the years 2002 to 2010 . This period coincides with a period of detailed measurements at Izaña (Rodríguez et al., 2011), and includes many of the measurements from our global compilation listed in the companion article (Perlwitz et al., 2015). We relax the model winds every $6 \mathrm{~h}$ toward their NCEP reanalysis values (Kalnay et al., 1996), in an effort to reproduce the observed transport. The winds are relaxed at all levels up to $10 \mathrm{hPa}$ with a globally uniform timescale of $100 \mathrm{~s}$. We 
also prescribe sea surface temperature and sea ice based upon measurements (Rayner et al., 2003).

Our baseline simulation is referred to as the "soil mineral fraction" (SMF) method, and assumes that the emitted mineral fractions are identical to those of the wet-sieved soil, given by Eq. (5). The wet-sieved soil fractions are derived using the MMT of Claquin et al. (1999), augmented by mineral fractions for three additional soil types provided by Nickovic et al. (2012). Following this latter study, iron oxides are extended into the clay-sized category using MMT fractions identical to their values for silt sizes. However, internal mixtures containing iron oxides are omitted from this simulation, so that this mineral is removed preferentially as a result of its higher density and rate of gravitational settling. Emission of each of the minerals at silt-sizes is apportioned over the ModelE2 size bins using an identical normalized mass distribution that represents an average over the model minerals observed at Tinfou, Morocco (Kandler et al., 2009), as described in the Supplement. The ratio of emitted clay to silt in the SMF experiment is given by the local soil texture.

Our new approach, hereafter described as the "aerosol mineral fraction" (AMF) method, is described in Sect. 2.2. The emitted mineral fractions are based upon the MMT soil mineral fractions, Eq. (5), modified to account for disaggregation during wet-sieving of mineral aggregates that would be emitted during brittle fragmentation of the original undispersed soil. The AMF method extends feldspar and gypsum into the clay fraction using Eqs. (15) and (16). For the other minerals, clay-sized emission derives from Eq. (11); siltsized emission is taken from Eq. (14). Allocation of emitted silt into the ModelE2 size bins is prescribed according to Eq. (18). Mixtures of iron oxides with other minerals are estimated according to Eqs. (30)-(32).

For the AMF simulation, our reaggregation parameter $\gamma$ is set equal to 2 . We performed a simulation with $\gamma=3.5$ to examine the sensitivity of our results to enhanced reaggregation. In addition, we set $\gamma=0$ in one experiment to illuminate the physical origin of differences between the AMF and SMF methods. The experiment with $\gamma=0$ uses an emitted size distribution consistent with measurements and the default AMF experiment, but resembles the SMF method by not reconstructing silt-sized aggregates to undo the effect of wet sieving.

We carried out two more experiments to show the effect of different treatments of iron oxides. The first is the AMF experiment but without accretions of iron oxides with other minerals (denoted by "AMF-NoFeAcc"). The second (denoted as "SMF-NoClayFe") corresponds to the SMF experiment, but without the extension of iron oxides into clay sizes proposed by Nickovic et al. (2012). Our simulations are summarized in Table 9.

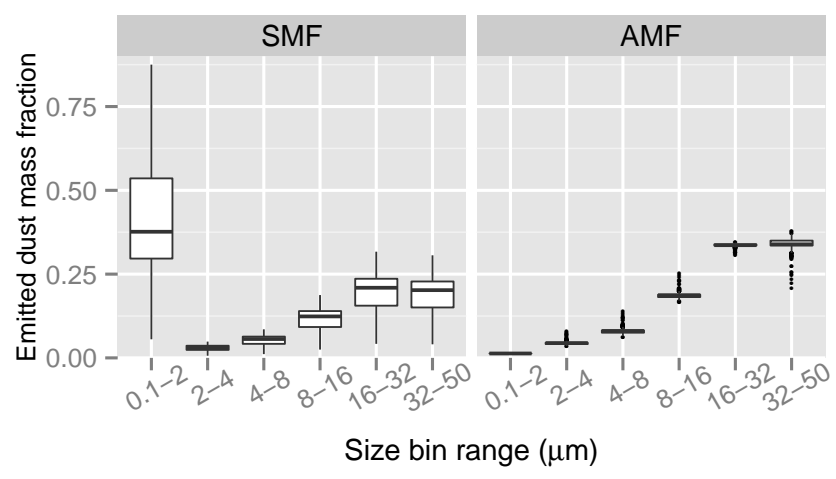

Figure 5. The distribution of the emitted dust mass fraction at each ModelE2 size bin for the soil mineral fraction (SMF) method (left) and the aerosol mineral fraction (AMF) method (right). Within each size bin, the box plots depicts the distribution with respect to the combinations of the 12 soil textures and the 28 arid soil types included in the MMT. For each combination, the sum over all sizes is one. At each bin, each combination within the distribution is weighted by the total emission (summed over all sizes) to emphasize prolific sources. Each box shows the range in which the central $50 \%$ of the data fall. The box borders show the first and third quartiles and the crossbar shows the median. Outliers exceeding the quartile values by more than a factor of 1.5 , the interquartile distance, are marked as points. Note that only diameters below $32 \mu \mathrm{m}$ are transported by the model.

\section{Results}

\subsection{Emitted size distribution and implications for long-range transport}

We first compare the emitted distributions of the AMF and SMF experiments summed over all minerals. This comparison and its implications for long-range transport help to understand regional variations of surface concentration for the individual minerals, presented in Sect. 4.3.

Figure 5 displays the fraction of mass emitted at each ModelE2 size bin according to the SMF and AMF methods. To construct this figure, we calculate the distribution of the emitted fraction within each size bin. The distribution is calculated using the 336 combinations of the twelve soil texture categories along with the twenty-eight DSMW soil types included in the MMT. For each combination of soil type and texture (characterized at the native resolution of the DSMW: $5^{\prime}$ latitude by $5^{\prime}$ longitude), emission is normalized so that the sum across all sizes is unity. To form the distribution, each combination at a particular size is weighted by the total emission (summed over all sizes) to emphasize prolific sources. The median emission is marked in the figure by a crossbar with variability among the different soil types and textures indicated as described in the caption.

For each SMF size bin, emission varies according to the local soil texture. For the AMF method, the size distribution varies additionally due to reaggregation of certain clay-sized 
Table 9. List of experiments ( $\mathrm{SD}=$ size distribution).

\begin{tabular}{ll}
\hline Experiment name & Comment \\
\hline SMF & Control (no reaggregation; emitted SD from local soil texture) \\
AMF & Default reaggregation parameter $(\gamma=2) ;$ emitted SD from measurements \\
AMF $(\gamma=0)$ & No reaggregation \\
AMF $(\gamma=3.5)$ & Increased reaggregation \\
AMF-NoFeAcc & No internal mixtures of iron oxide with other minerals $(\gamma=2)$ \\
SMF-NoClayFe & No clay-sized iron oxide \\
\hline
\end{tabular}

minerals dispersed in the wet-sieved soil. For clay-sized particles (Fig. 5), the median SMF fractional emission is 0.325 , which is large compared to the AMF clay-sized fraction of 0.013 that is prescribed and spatially uniform, based upon observations of the emitted size distribution (cf. Eq. 10) and the normalized volume fractions at Tinfou that we assume are universal. At silt sizes, the median of the sum of the AMF emission is also spatially uniform by prescription (cf. Eq. 12). Thus, individual AMF bins at silt sizes exhibit smaller variability, compared to the SMF method, whose silt fraction varies with the local soil texture.

The annual-mean AMF surface concentration for different particle sizes is shown in Fig. 6a, b and c, along with its ratio with respect to the SMF values in Fig. 6d-f. The AMF global mean is $8.27 \mu \mathrm{g} \mathrm{m}^{-3}$, consisting of 0.47 and $7.79 \mu \mathrm{g} \mathrm{m}^{-3}$ at clay and silt sizes, respectively. The largest concentrations are located near the main source regions, including the Sahara and Sahel, the Arabian Peninsula, and Central Asia, where concentrations can exceed $500 \mu \mathrm{g} \mathrm{m}^{-3}$. Large amounts of dust are also found in eastern Asia, Australia, and Patagonia, and smaller, yet regionally significant dust concentrations originate from source regions in the Great Plains of North America and Kalahari in southern Africa. The global surface concentration in the AMF experiment is less than half of its corresponding SMF value (Table 7, and Fig. 6d), a contrast that is also reflected in the aerosol load (Fig. 7). The reduced AMF concentration and load occurs despite the prescription of identical total emission in both simulations (Fig. 8). (See Supplement Figs. S4 to S15 for gravitational settling, dry and wet deposition, and lifetime.) The smaller concentration and load in the AMF experiment results from its different assumption about the emitted size distribution compared to the SMF model. The SMF size distribution is determined by the local soil texture and its specified fractions of clay and silt-sized particles. In contrast, emission of the clay soil fraction is inhibited in the AMF model, an empirical constraint motivated by emission measurements. This results in a greater AMF silt fraction, compared to the SMF model. The larger particles are removed more quickly by gravitational settling, resulting in a smaller load and surface concentration in the AMF experiment. The reduction of AMF surface concentration compared to the SMF value is smallest over source regions, whereas the largest decreases are ob- served in remote regions of the tropics at the end of long trajectories marked by contrasting rates of settling (Fig. 6d). The ratio of AMF global surface concentration at clay diameters compared to the SMF value is 0.05 (Fig. 6e), comparable to the ratio of clay emission (Fig. 8). This reflects the similar lifetime of clay particles in both experiments, indicating wet removal as the common process that dominates particle removal. At silt sizes, the global AMF concentration is $61 \%$ larger than the SMF value (Fig. 6f), reflecting larger emission at this size in the former experiment. Note that the largest absolute contrasts between the two experiments (not shown) would be found near source regions, where total concentrations are several orders of magnitude higher than in remote regions.

\subsection{Emitted mineral mass fractions}

Contrasts between the experiments are apparent in the emitted fractions of the individual minerals, shown in Fig. 9. Within each size bin, distributions are calculated as in Fig. 5. The mass fractions are normalized so that within each size bin, their sum over all minerals is unity. This normalization is chosen to show the minerals making the largest median contribution to each size bin. To complement these fractions, the magnitude of global annual emission for each mineral and each size bin is shown in Fig. 8.

The SMF method emits clay-sized dust aerosols that are comprised mostly of phyllosilicates with median values of 0.40 for illite, 0.22 for smectite and 0.19 for kaolinite (Fig. 9, green). SMF phyllosilicates are absent among siltsized aerosols, which are comprised mainly of quartz and feldspar, whose median values are 0.70 and 0.21 , respectively. In the AMF, the mass fractions of clay-sized phyllosilicates are slightly reduced in comparison to the SMF, offset by increases of feldspar and gypsum (Fig. 9, orange). However, the AMF reintroduces phyllosilicate aggregates at silt sizes that are absent in the wet-sieved soil. This reintroduction is in proportion to $\gamma$, which is set equal to 2 in our reference AMF simulation. A consequence of this reintroduction is to substantially reduce the quartz and feldspar fractions in the silt size range (Fig. 9). Carbonate fractions at silt sizes are slightly increased compared to the SMF, particularly in the smallest silt-size model bins, due to the prescribed reaggregation of clay-sized soil particles. 

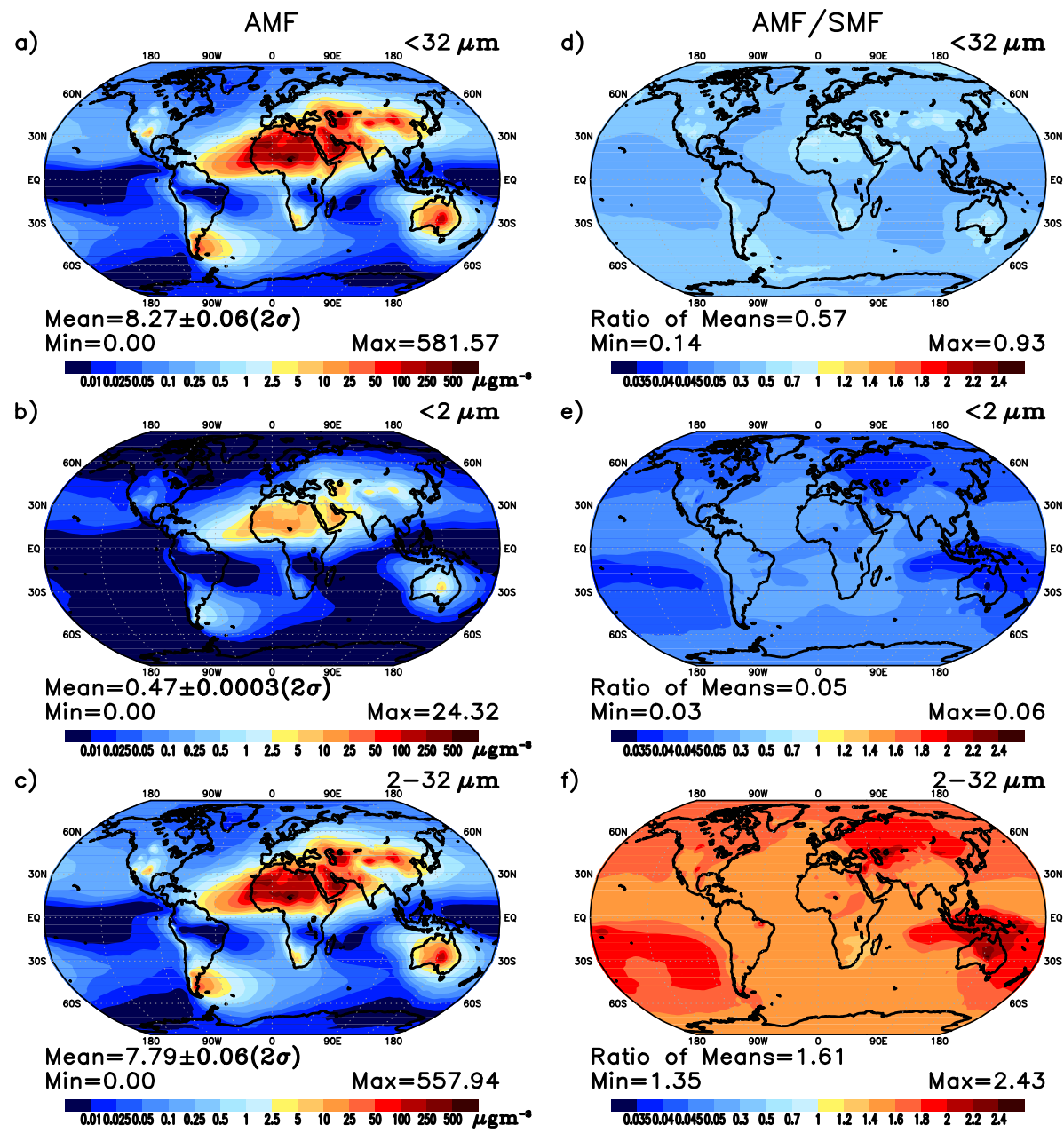

e)
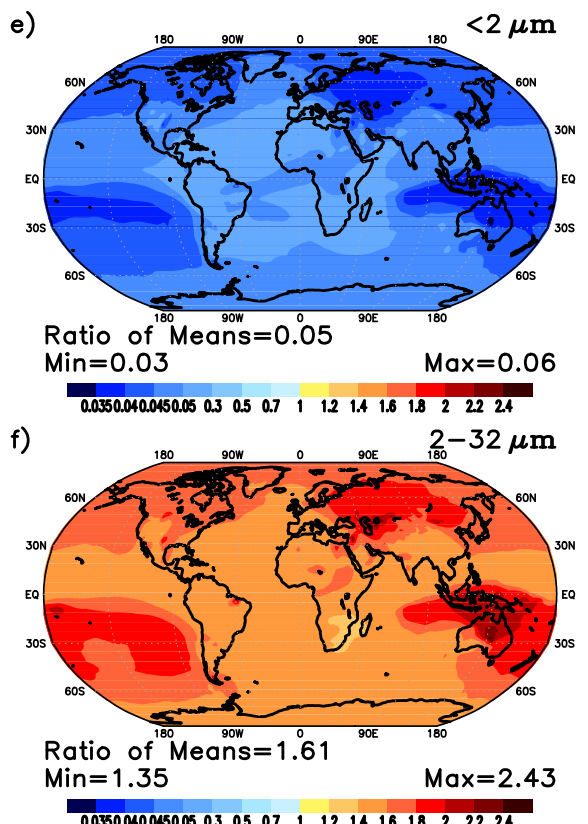

Figure 6. (Left panels) Annual-average surface concentration (summed over all minerals) for the AMF method and (right panels) the ratio of the AMF and SMF concentrations for (a), (d) total dust; (b), (e) clay-sized dust; and (c), (f) silt-sized dust.

In the AMF method, the emitted silt mass of each mineral is distributed empirically across the model size categories using the normalized volume fraction derived for each individual mineral based upon measurements at Tinfou (cf. Eq. 18 and Fig. 4). In contrast, silt emission in the SMF method is distributed identically for all minerals using the average normalized distribution. (This is why the SMF emitted fractions in Fig. 9 are identical across all the silt size categories.) This contrast between the methods has significant effects upon the quartz fraction, for example, whose emission in the AMF experiment is distributed towards the larger silt size bins (Fig. 4). Consequently, the truncated fraction of quartz emission with diameters above $32 \mu \mathrm{m}$ (whose transport is not calculated by the model) is larger in the AMF simulation compared to the SMF method.

Figure 9 (black) displays the emitted mineral fractions for the AMF experiment, but without reaggregation of clay particles $(\gamma=0)$. The size distribution of dust mass summed over all minerals in this simulation (not shown) resembles that of our reference AMF simulation (Fig. 6), because it necessarily satisfies Eq. (10). However, the effect of $\gamma=0$ is to preclude the reaggregation of clay soil particles that would otherwise be emitted at silt sizes. The median fractions of quartz and feldspar in the silt size bins are higher than in the AMF experiment due to the absence of reaggregated phyllosilicates. This experiment will be used to identify the physical origin of contrasting behavior between the AMF and SMF methods in the companion article (Perlwitz et al., 2015).

\subsection{Regional variations of the mineral fractions}

\subsubsection{Emission}

The regional variations of emitted mineral fractions are displayed for illite and kaolinite (Fig. 10), quartz and carbonates (Fig. 11), and feldspar, gypsum, and iron oxides (Fig. 12). The left column shows the AMF emitted fraction, while the right column shows its ratio with respect to the SMF value. These global maps are shown at model resolution $\left(2^{\circ} \times 2.5^{\circ}\right.$ 

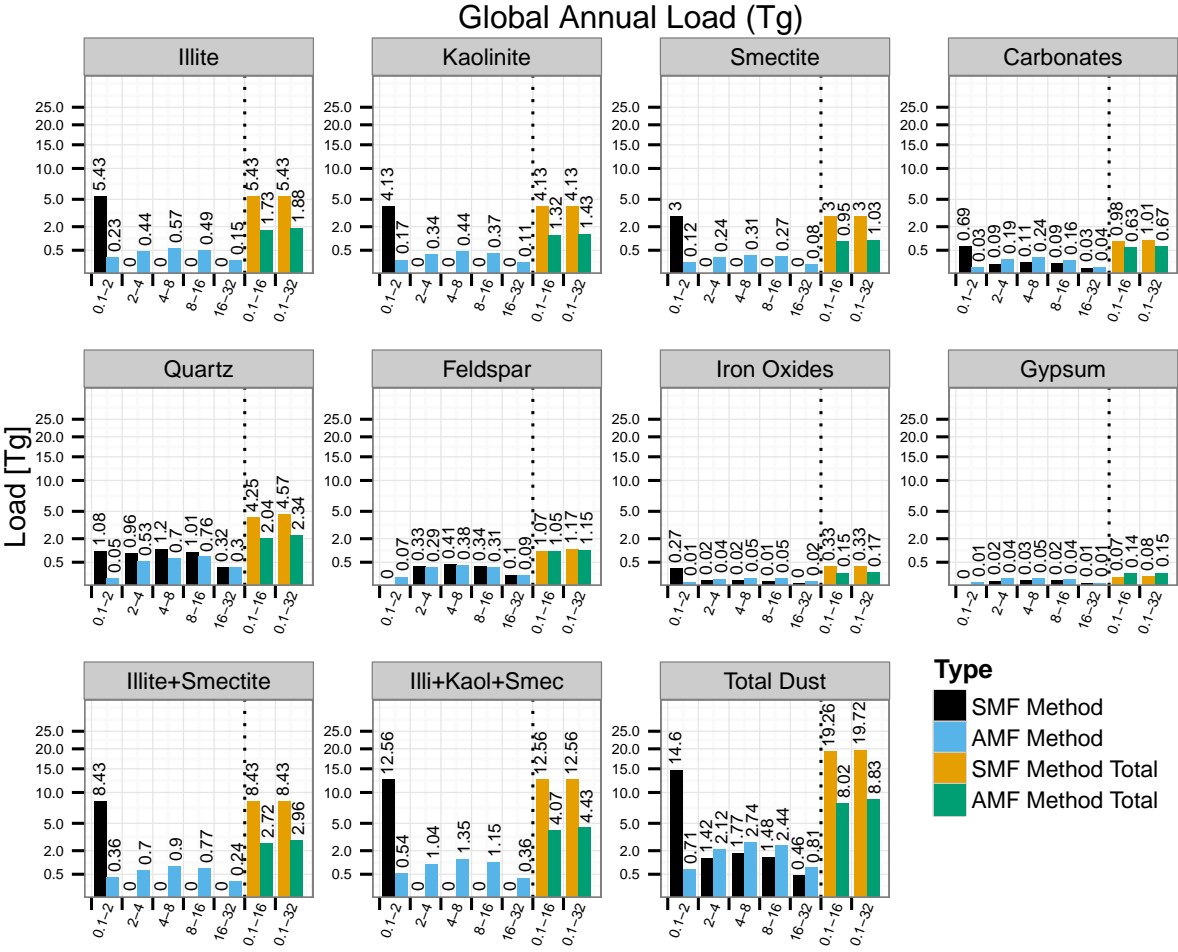

Type

SMF Method AMF Method

SMF Method Total

AMF Method Total

Size Class $[\mu \mathrm{m}]$

Figure 7. Global annual load (Tg) for the AMF and SMF experiments.
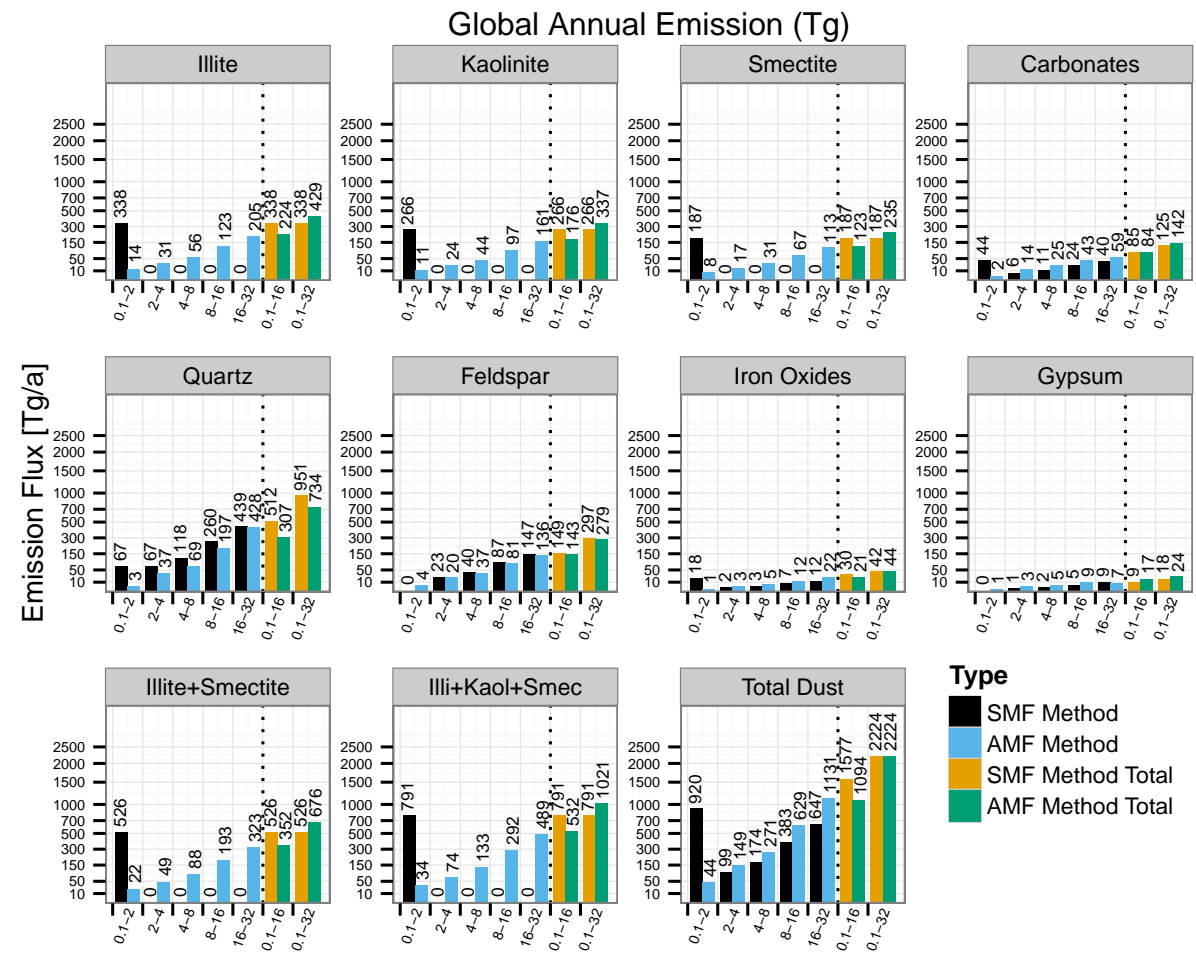

Type

SMF Method

AMF Method

SMF Method Total

AMF Method Total

Size Class $[\mu \mathrm{m}]$

Figure 8. Global annual emission (Tg) for the AMF and SMF experiments. 


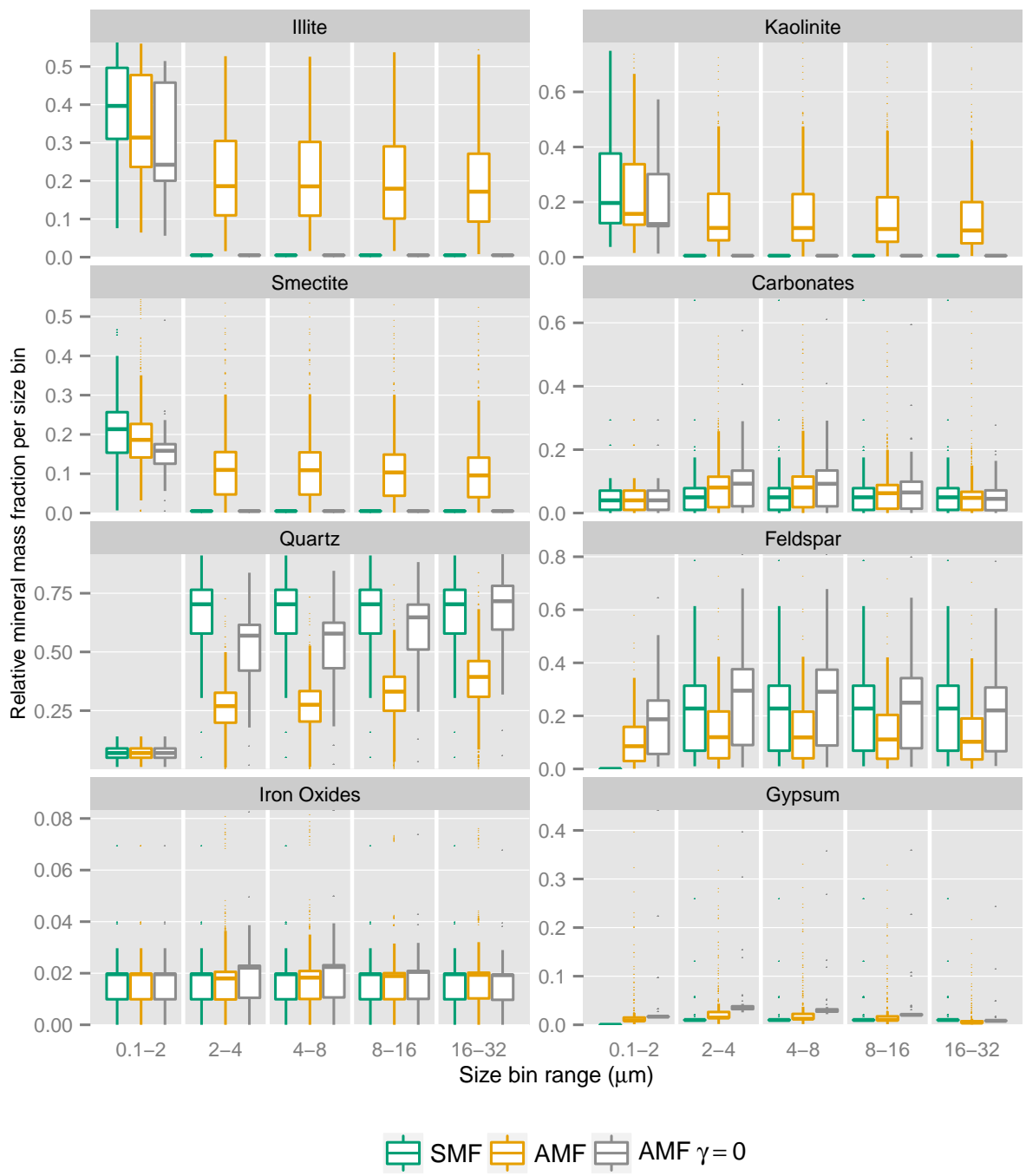

Figure 9. The distribution of the emitted mass fraction of each mineral at each ModelE2 size bin for the soil mineral fraction (SMF) method (green), the aerosol mineral fraction (AMF) method (orange), and the AMF method with $\gamma=0$ (black). The box plots are constructed as in Fig. 5, but the emitted mineral fractions sum to unity within each separate size bin, to identify the mineral making the largest contribution to emission at that size.

latitude by longitude) and include only regions where dust emission occurs in our model. (Maps covering all soils where the MMT is applicable are provided in Figs. S1-S3 of the Supplement. Note that the extreme values depicted in the box plots in Fig. 9 are smoothed out at the model resolution due to spatial averaging.)

The AMF global fraction of emitted illite is $33 \%$ at clay sizes (Fig. 10a) and $19 \%$ over all sizes (Fig. 10b). The largest fractions are found in northern Africa (specifically in Erg El Djouf between Mali and Mauritania, the Libyan Desert and the Qattarah Depression in Egypt), the Middle East (southern Saudi Arabia and Mesopotamia), Turkmenistan, the Tarim Basin and the Inner Mongolia deserts in East Asia, southern Australia, and the southern African coastal region. The AMF kaolinite global fraction is $25 \%$ in the clay size range and $15 \%$ for all sizes (Fig. 10c and d). In general, kaolin- ite is largest where the illite fraction is lowest, specifically in the Sahel region, northwestern India, the Kalahari Desert in southern Africa and western Australia.

Illite, kaolinite, and smectite (the latter not shown) are absent at silt sizes in the SMF. The AMF experiment extends these phyllosilicates into the silt size range (the size at which the prescribed fraction of emission is largest according to Fig. 5). This reaggregation is in proportion to their fraction as clay-sized particles in the wet-sieved soil, and results in an average emission increase when summed over all sizes of $27 \%$ compared to the SMF (Fig. 10f and h). The global phyllosilicate fraction is decreased at clay sizes compared to the SMF by roughly $10 \%$ (Fig. 10e and g) due to the inclusion of feldspar and gypsum by the AMF method.

The AMF global fraction of emitted quartz is roughly $7 \%$ in the clay size range (Fig. 11a) and $34 \%$ at silt sizes 

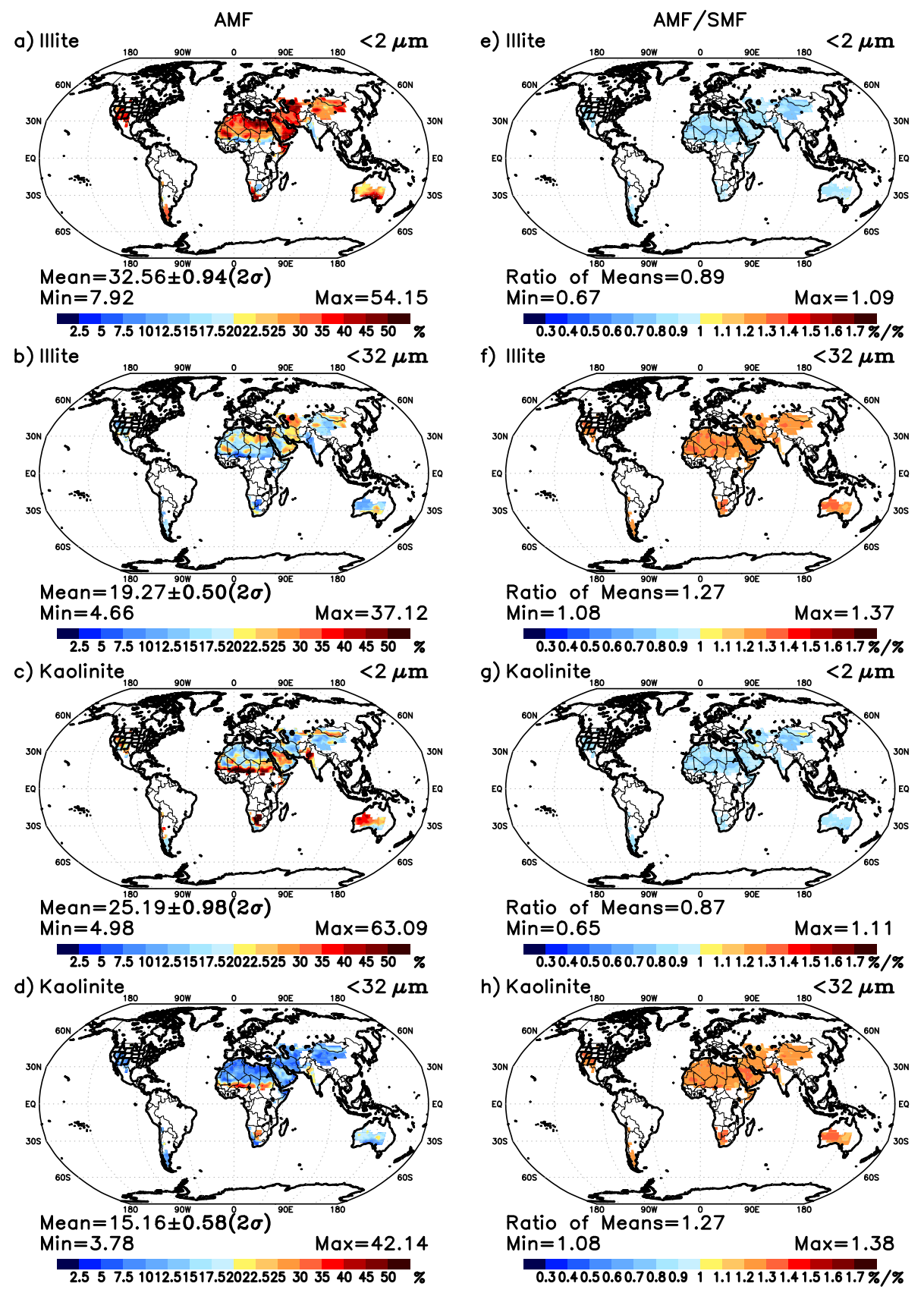

Figure 10. Annual-average fraction of emission of (a), (b) illite and (c), (d) kaolinite at clay and all sizes for the aerosol mineral fraction (AMF) method. The right column shows the ratio of fractional emission for the AMF and soil mineral fraction (SMF) methods for (e), (f) illite and (g), (h) kaolinite.

(Fig. 11b), with the largest values in sandy regions of southern Africa (Kalahari desert), northern Africa (Erg El Djouf between Mali and Mauritania, the Libyan Desert, northern Algeria and the Grand Erg of Bilma in Niger), northwestern India, southern Saudi Arabia, Turkmenistan and the Tarim Basin. Compared to the SMF, AMF quartz fractions are similar for clay sizes (Fig. 11e) and are lower by half in the silt size range (Fig. 11f).
The AMF global fraction of emitted carbonate is 5 and $6 \%$ at clay and silt sizes, respectively (Fig. $11 \mathrm{c}$ and d), with the largest values in the North African coastal source regions (Algeria, Lybia and Egypt), Mesopotamia, the southern coast of the Saudi Arabia, the Iran-Afghanistan region, the Ganzu province in China, and the southern coasts of Africa and Australia. Carbonate fractions are low (less than $1 \%$ ) in the Sahel and the Kalahari Desert in southern Africa. At the native 

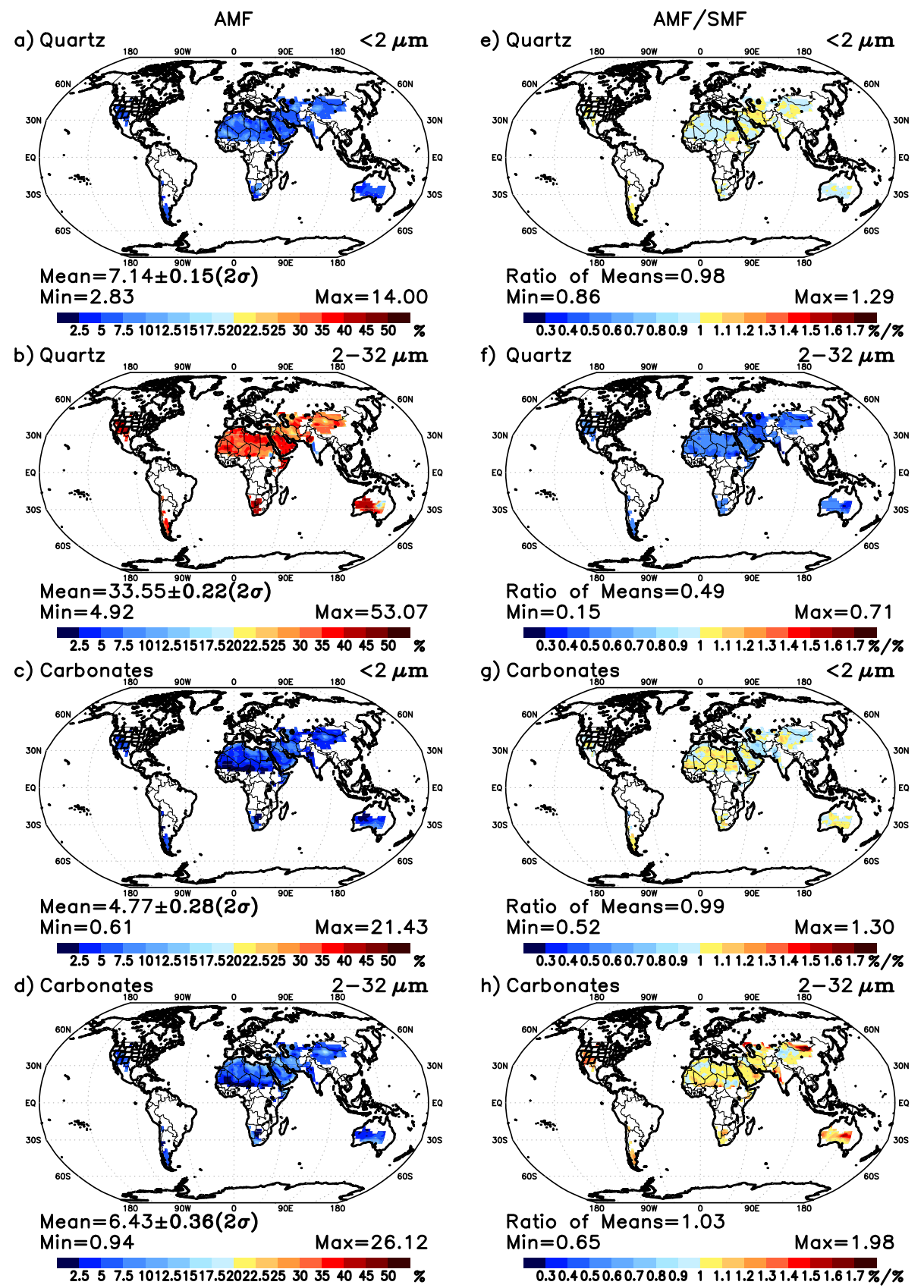

Figure 11. Fractional emission as in Fig. 10 but for clay and silt-sized quartz and carbonates.

resolution of the soil texture and type databases, the emitted fractions of clay-sized quartz and carbonate are prescribed to be identical between the AMF and SMF experiments. The small differences in Fig. 11e and $\mathrm{g}$ arise when regridding to the coarser ModelE2 resolution. (The emission of each mineral is regridded by averaging over the higher resolution of the soil databases within each ModelE2 grid box. This emission is the product of the mineral fraction and the total claysized emission that is summed over all minerals. The claysized emission is uniform within the model grid box for the
AMF experiment (according to Eq. 10), but varies within this area in the SMF experiment as a result of variations of soil texture, accounting for the contrast in Fig. 11e and g.)

The AMF global fraction of emitted feldspar is roughly $13 \%$ at both silt and all sizes (Fig. 12a and b), with the largest values in northern Africa (southern Algeria, northern Mauritania and northern Niger) and south of the Tarim Basin in East Asia. Compared to the SMF experiment, the AMF global silt fraction of feldspar is $45 \%$ lower (Fig. 12e) due 

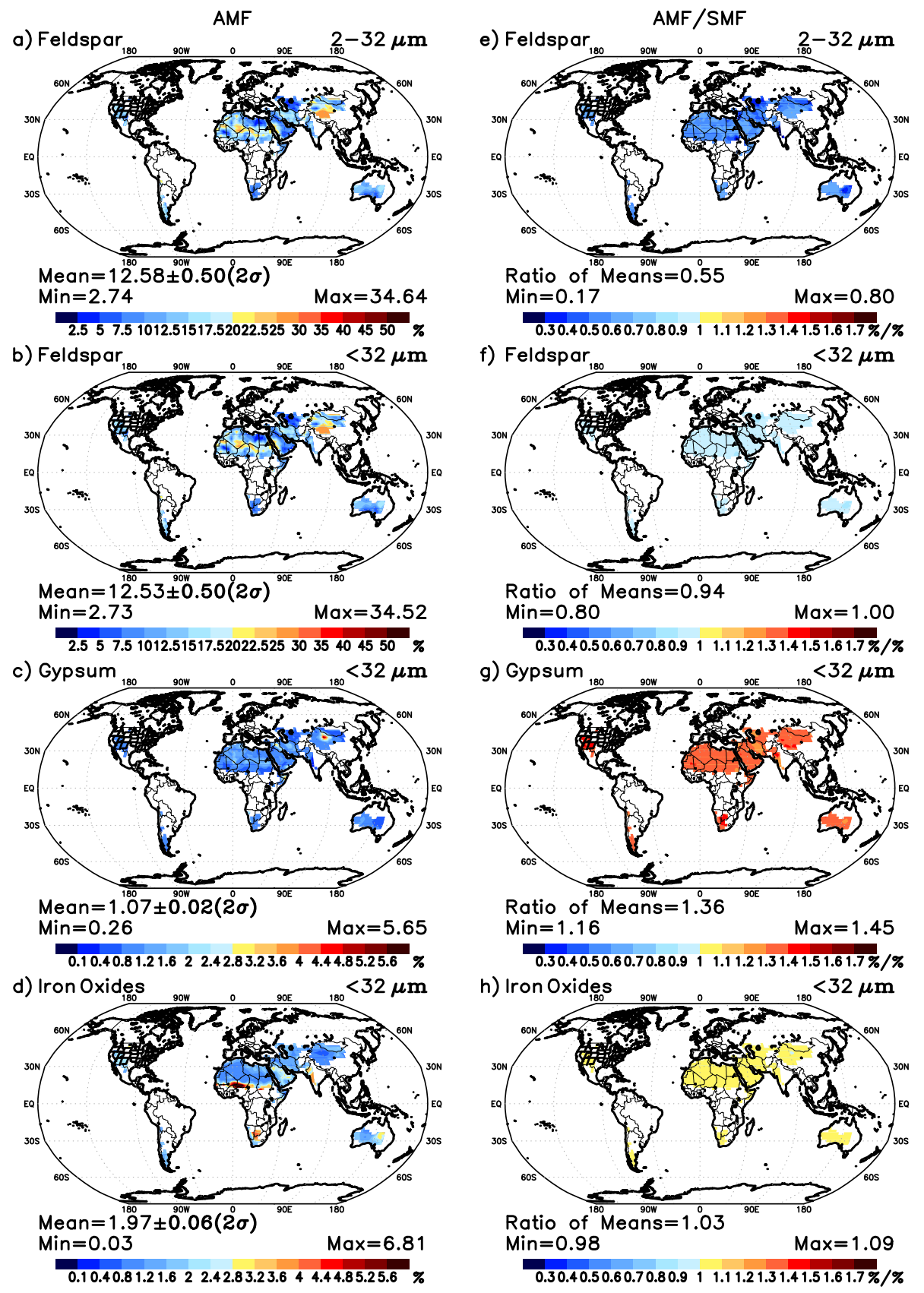

Figure 12. Fractional emission as in Fig. 10 but for feldspar (silt-sized and total), gypsum and iron oxides.

to the reintroduction of phyllosilicate aggregates, although at all sizes the fractional reduction is only $6 \%$ (Fig. 12f).

Emission of gypsum and iron oxides is comparatively small, with local fractions never exceeding a few percent. The global emitted fraction of iron oxides is nearly identical in the AMF and SMF experiments (Fig. 12h). This agreement is fortuitous, resulting from the competing effects of reaggregation at silt sizes in the AMF experiment offset by the larger emitted clay fraction in the SMF experiment (Fig. 8). Emission of iron oxides is largest within the Sahel (Fig. 12d), where dust collected downwind is distinguished by its reddish color (Carlson and Prospero, 1972). Smaller enrichment of iron oxides is seen within the Kalahari Desert of southern Africa, as well as eastern Australia along with the Thar Desert and maritime foothills of the Western Ghats within the Indian subcontinent. 

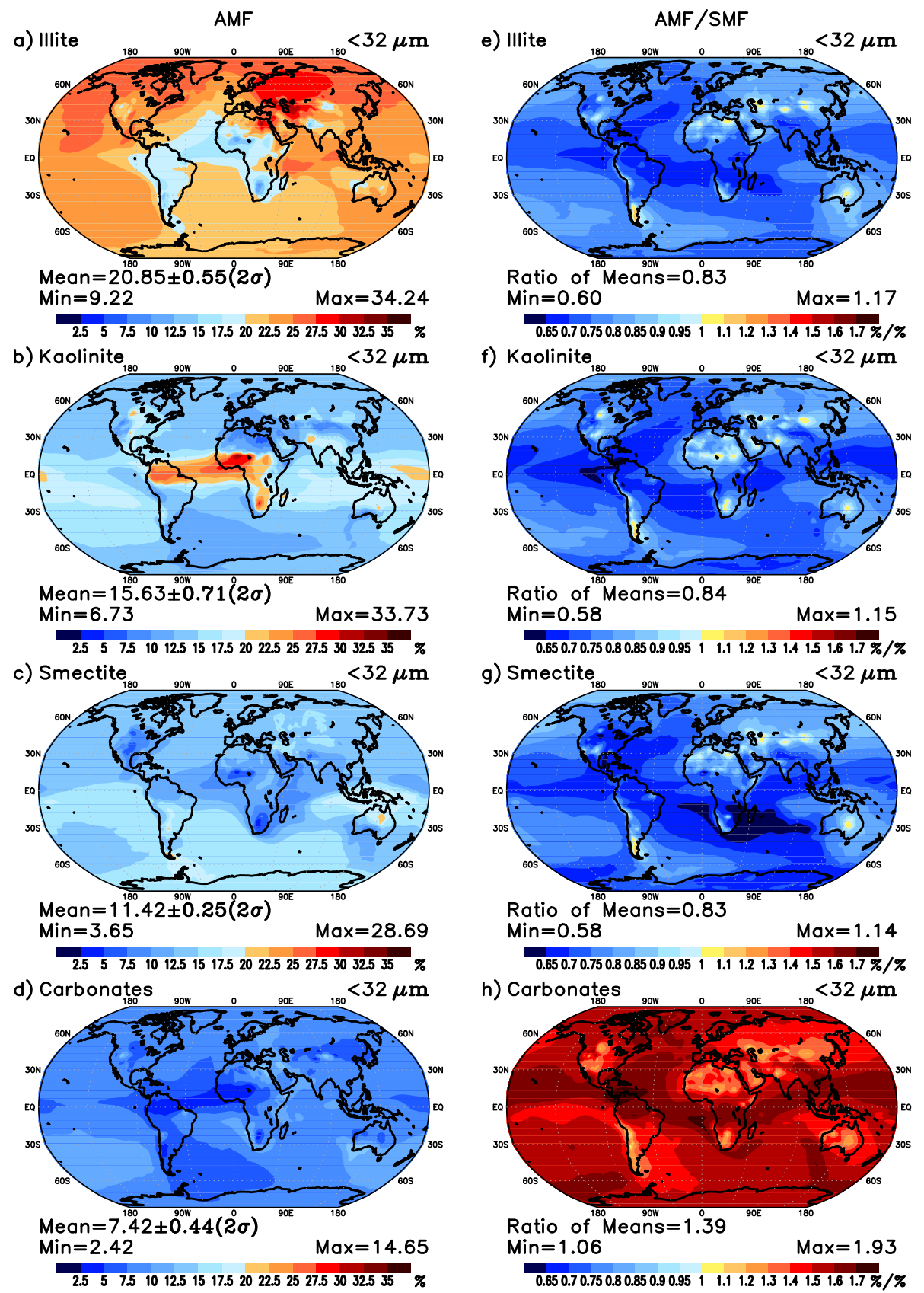

Figure 13. Annual-average fraction of surface concentration for (a) illite, (b) kaolinite, (c) smectite, and (d) carbonates for the AMF method. The right column shows the ratio between the AMF and the SMF fractions for (e) illite, (f) kaolinite, (g) smectite, and (h) carbonates.

\subsubsection{Surface concentration}

Figures 13 and 14 display the global distribution of the annual-average mineral fractions in surface concentration for the AMF, along with their ratio with respect to the SMF fractions.

Attribution of the mineral fractions to contrasts between the AMF and SMF methods is challenging because the fractional surface concentration depends upon the interaction of numerous processes including the size dependence of emission and removal, along with the proximity of sources enriched or depleted in different minerals. Nonetheless, the figures illustrate the effect of some physical assumptions underlying the methods. For example, the AMF kaolinite and iron oxide fractions are large downwind of the Sahel and southern Africa (Figs. 13b and 14c), where the source regions are enriched in these minerals (Figs. 10 and 12). Similarly, the fractional concentrations of quartz and feldspar are enriched 

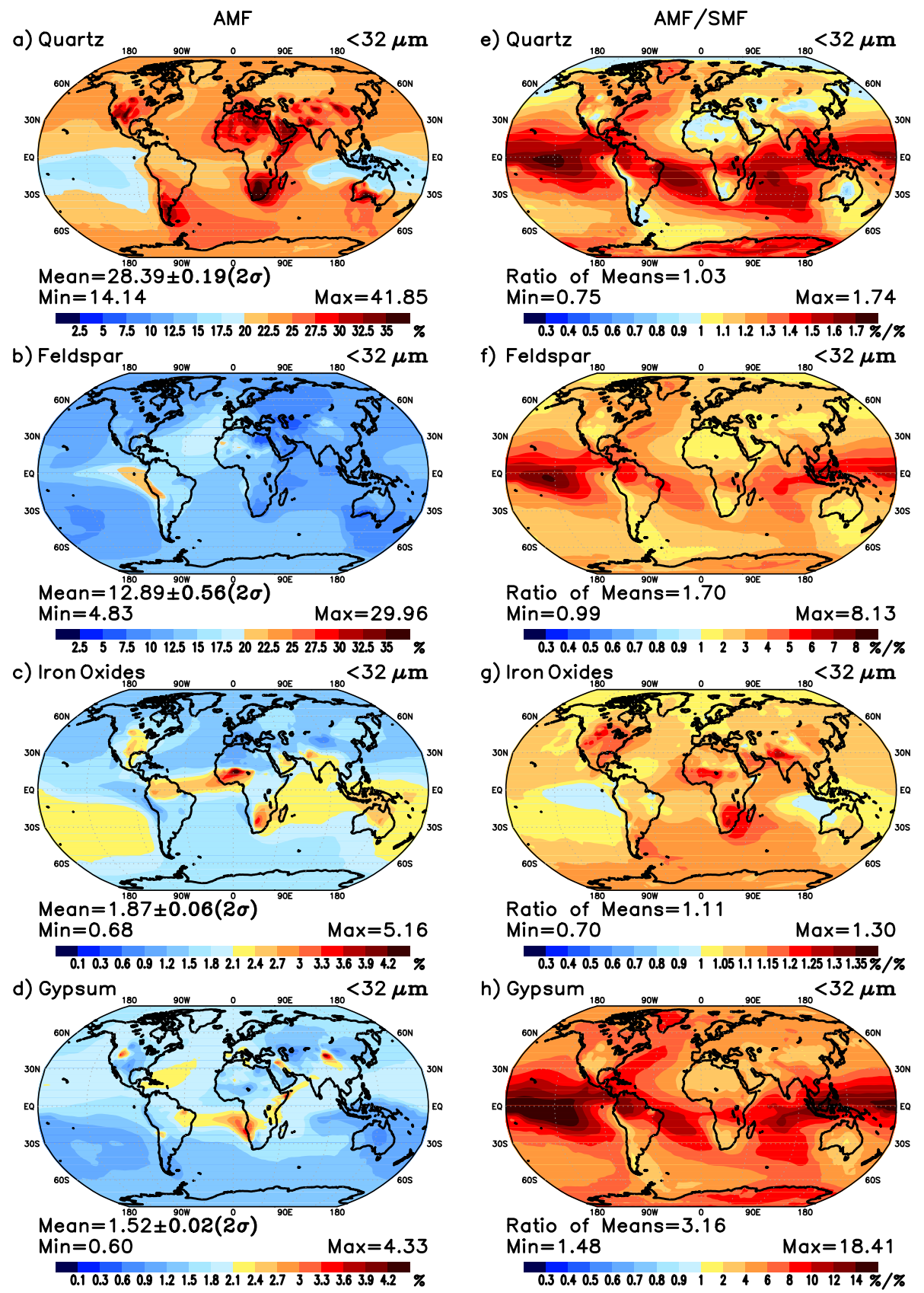

Figure 14. Fractional surface concentration as in Fig. 13 but for (a), (e) quartz, (b), (f) feldspar, (c), (g) iron oxides, and (d), (h) gypsum. Note that the color scale varies among panels to represent regional variations in mineral fractions.

along the Pacific coast of South America (Fig. 14a and b), reflecting their origin from local sources, including Patagonia, along with the shielding effect of the Andes that limits transport from Africa. Conversely, the tropical western Pacifc is depleted in quartz and gypsum (Fig. 14a and d), because emission of these minerals is relatively small upwind over Australia. In general, the concentration of illite is inversely related to that of kaolinite (Fig. 13a and b), reflecting the contrasting weathering processes that create each mineral in the source soil.

Differences between the AMF and SMF methods are also illustrated. Far from source regions, clay-sized particles dominate the concentration. Thus, the difference of the clay-sized fractions of emission determines approximately whether the concentration of a particular mineral in remote regions is larger according to one method. (This relation is approximate, because the smallest silt particles have lifetimes that 

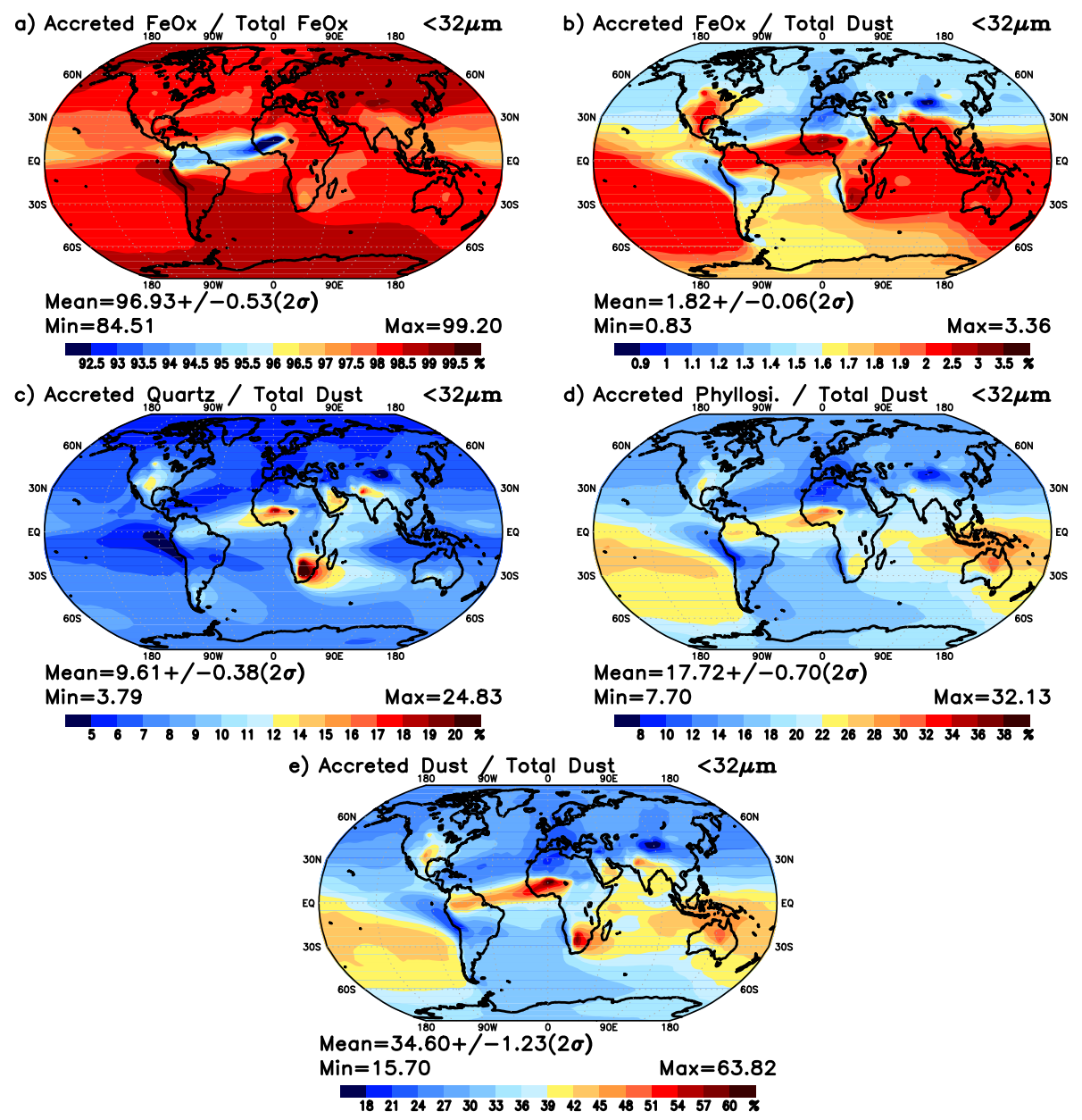

Figure 15. Annual-average column mass fraction of (a) accreted iron oxide relative to total iron oxide, and (relative to total dust) accreted (b) iron oxide, (c) quartz, (d) phyllosilicate (illite + kaolinite + smectite) and (e) dust.

are only slightly shorter.) The clay-sized fraction of phyllosilicates is smaller in the AMF experiment (Figs. 9), so their ratio with respect to the SMF decreases downwind (Fig. 13e-g). This contrast is enhanced by the greater SMF fractional emission of clay particles (Fig. 5) that reduces the offsetting effect of phyllosilicate emission within the smallest silt size category in the AMF simulation. Conversely, the ratios of gypsum and feldspar increase downwind (Fig. 14f and $\mathrm{h}$ ), because clay-sized emission of these minerals occurs only in the AMF experiment. The ratio of AMF quartz also increases downstream (Fig. 14e), although attribution is more elusive, because the emitted clay-sized fraction is nearly identical in both experiments. In general, the globalmean ratio of the AMF and SMF fractional concentration for each mineral is consistent with the ratio of the two experiments far from the source.

Immediately downwind from a source region enriched in phyllosilicates and iron oxides, the ratio of the AMF and SMF fractional concentration decreases (Figs. 13e-g and $14 \mathrm{~g}$ ). This is because their emission is peaked toward larger sizes in the AMF experiment, so that the fractional concentration of a particular mineral falls off within a shorter distance of a source region where it is enriched.

\subsection{Iron oxides: pure vs. accreted forms}

The fraction of the iron oxide in accreted form is shown in Fig. 15a. The accreted fraction (derived from the aerosol load) is smallest downwind of the Sahel and other source regions enriched in iron oxides (Fig. 15a). These minima are a consequence of our mixing assumption, Eq. (23), that increases the fraction of pure crystalline iron oxide where the soil is enriched in this mineral (Fig. 12g). The accreted fraction increases downwind as the pure crystalline form is removed preferentially by gravity due to its greater density.

Regions where the soil is enriched in iron oxides correspond to a maximum of accreted iron oxide mass relative to the total dust mass (Fig. 15b), even if a larger proportion of this mineral is in pure crystalline form (Fig. 15a). This is a consequence of our partitioning assumption (Eq. 25) and the 
small value of $a_{\mathrm{Fe}, k}$ that represents the soil fraction of iron oxides. The AMF global mass fraction of accreted iron oxide is $1.82 \%$, within the range of values typically assumed by models that relate dust radiative properties to (globally uniform) prescribed mineral composition (Sokolik and Toon, 1999; Balkanski et al., 2007). This fraction results from two assumptions in our model: first, that iron oxides are $5 \%$ of the particle mass (Eq. 26), and second, that the assumed fraction of accreted iron oxide decreases in enriched soils, according to Eq. (23) and our choice of $\epsilon_{0}$. There are few observations to constrain precise values of either of these parameters, although the primary contribution of iron oxide to measured aerosol radiative absorption offers an indirect constraint. The accreted fraction is probably insensitive to a range of $R$. A larger prescribed value would distribute the accreted iron oxide over fewer particles, while a smaller value would result in accretions within more particles. The accreted fraction of iron oxides in our model is presumably more sensitive to the prescribed partitioning of crystalline and accreted forms according to Eq. (23) that is a heuristic attempt to represent the effect of soil weathering.

The fraction of quartz and phyllosilicates containing iron oxide accretions compared to the total dust mass is shown in Fig. 15c and d, respectively. This fraction is largest in regions enriched in iron oxides, but also where the fractions of the host minerals are large, according to Eq. (27). The total fractional mass of dust particles containing accretions is largest downwind of soils enriched in iron oxides (Fig. 15e). The global mass fraction is $34.60 \%$. We can calculate the effective mixing fraction of iron oxide to the total particle mass as $\frac{1.82}{34.60+1.82}=0.04997$ that can be compared to our chosen value of $R=0.05$. The discrepancy originates within regions of iron oxide-rich soils, where the accreted fraction, given by Eq. (25), is so large that there is an insufficient supply of other minerals available for mixing (necessitating the minimum operator as an upper bound in Eq. 30). The small difference between the prescribed value of $R$ and its effective value indicates that the exhaustion of other minerals available to host accretions occurs at only a few locations.

We carried out additional experiments to illustrate the effect of our model assumptions for iron oxides and its mixtures (Table 9, and Figs. S16 and S17 in the Supplement). The introduction of iron oxides at clay sizes following Nickovic et al. (2012) results in global iron oxide mass that is five times larger compared to the SMF-NoClayFe experiment that emits iron oxides only at silt sizes following Claquin et al. (1999). This contrast results from the large fraction of clay particles in the wet-sieved soil characterized by Claquin et al. (1999) and the correspondingly large emission of iron oxides at clay sizes.

The effect of accretions is shown by contrasting the AMF and AMF-NoFeAcc experiments. The iron oxide mass at clay sizes is nearly identical in the two experiments because removal of this particle size is dominated by wet deposition that is independent of particle density. However, at larger silt sizes, whose concentration is more vulnerable to removal by gravitational settling, the AMF experiment with accretions has a global iron oxide mass that is larger by $40 \%$.

\subsection{Evaluation at Tinfou, Morocco}

An extensive comparison of the model to observations is deferred to a companion article (Perlwitz et al., 2015), where we use a global compilation of measurements from almost sixty studies. Here, we compare to measurements only at Tinfou, Morocco, where the mineral fractions are characterized in exceptional detail (Kandler et al., 2009). These measurements demonstrate how processes represented by the AMF method (such as reaggregation) lead to improved agreement, but also show the limitations of other model assumptions, identifying the need for future model development.

Figure 16 shows the fractional contribution of each mineral to surface concentration. (Calculation of the observed mineral fractions is described in the Supplement.) These fractions sum to unity within each size bin, so that comparison to measurements shows each model's ability to reproduce the fractional contribution of minerals within separate size classes. In the SMF experiment, phyllosilicates are missing from all silt-size bins, as are feldspar and gypsum at clay sizes; both are contrary to measurements. The AMF method improves the phyllosilicate comparison through reaggregation that restores this mineral to the silt range. Another distinctive feature of the SMF experiment is the strong overestimation of the quartz fraction at silt sizes. This is largely corrected by the AMF method that increases the phyllosilicate fraction of emitted silt at the expense of quartz. This is shown by the AMF fractions calculated with $\gamma=3.5$, where enhanced reaggregation at silt sizes leads to an additional increase of phyllosilicates and a reduction of quartz. Both the AMF and SMF experiments overestimate kaolinite at clay sizes, and this common error suggests that the kaolinite fraction is overestimated by the MMT (although other processes like transport can contribute to the error). The AMF method also overestimates the kaolinite fraction at silt sizes. The AMF kaolinite fraction at this size is sensitive to its prescribed MMT fraction at clay sizes due to reaggregation, as shown by the increased error for $\gamma=3.5$.

Feldspar is the exceptional mineral where the SMF fraction is more realistic at all silt sizes. The AMF experiment underestimates the measured feldspar fraction, although it predicts a non-zero fraction at clay sizes in contrast to the SMF experiment. In the companion article, we show that the AMF feldspar fraction is generally in better agreement at other locations. Both methods underestimate the iron oxide fraction, and the discrepancy of the SMF value increases with particle diameter. The relatively large density of the pure crystalline form enhances gravitational removal, reducing the particle lifetime as diameter increases. In contrast, the internal mixtures present only in the AMF experiment 

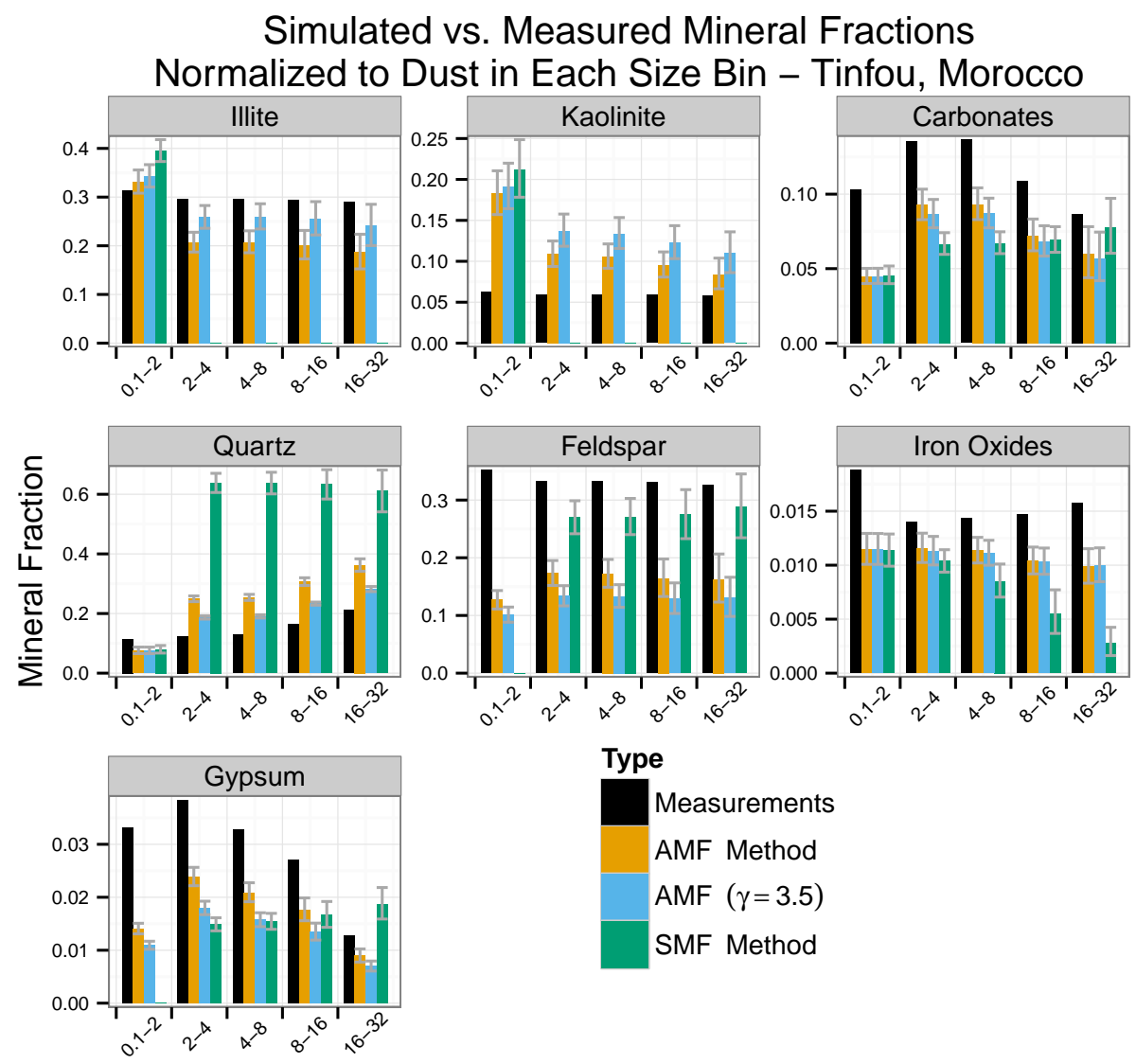

\section{Size Class $[\mu \mathrm{m}]$}

Figure 16. Mineral fractions of surface concentration relative to total dust concentration. Values at Tinfou, Morocco, are calculated from volume fractions of minerals and number of total dust particles provided by Kandler et al. (2009) along with mineral densities from Table 8 , as described in the Supplement. Model values are from the SMF, AMF and AMF $(\gamma=3.5)$ experiments. The sum of mineral fractions within each size bin equals 1 . Smectite is not included as it is not distinguished by the measurements. The uncertainty bars correspond to 2 standard errors.

are removed more slowly, reproducing the measured weak dependence of the iron oxide fraction upon particle size.

Figure 17 shows mineral fractions, but without separate normalization within each size bin. That is, the fractions sum to unity over all minerals and all sizes. Fidelity in comparison to the measurements at Tinfou depends additionally upon the ability of each experiment to reproduce the measured size distribution (rather than just the mineral fractions within each individual size category that are presented in Fig. 16). Note that we apportion the emitted silt using only the normalized volume distribution measured at Tinfou, so that the comparison in Fig. 17 depends additionally upon the calculated magnitude of emission at the contributing sources.

The SMF experiment strongly overestimates the mineral fractions at clay sizes due to its relatively large emission at this size (Fig. 8). In contrast, the AMF fractions are closer to the measured values. The most consistent error in the AMF experiment is an underestimate of each mineral fraction within the largest size category. This behavior is partly the result of using measurements after transport from the source to distribute the emitted mass within the silt size bins according to Eq. (18). The emitted size distribution is modified by deposition, which preferentially removes the largest particles by gravitational settling. We try to limit the influence of deposition by using measurements during times of high number concentration when emission is presumably recent. However, the use of measurements after transport will inevitably lead to a negative bias at the largest sizes that future model versions will have to address.

Feldspar and the phyllosilicates are difficult to distinguish within single particles using X-ray diffraction (XRD) due to the small sample mass, so Kandler et al. (2009) assign the same volume fraction to each mineral within each size category (Fig. 4). Measurements of elemental composition (their Fig. 14) suggest that the mass of feldspar increases relative to phyllosilicates at larger silt sizes. The uncertain distinction between the measured size distributions of feldspar and phyllosilicates influences the transport of both minerals. 

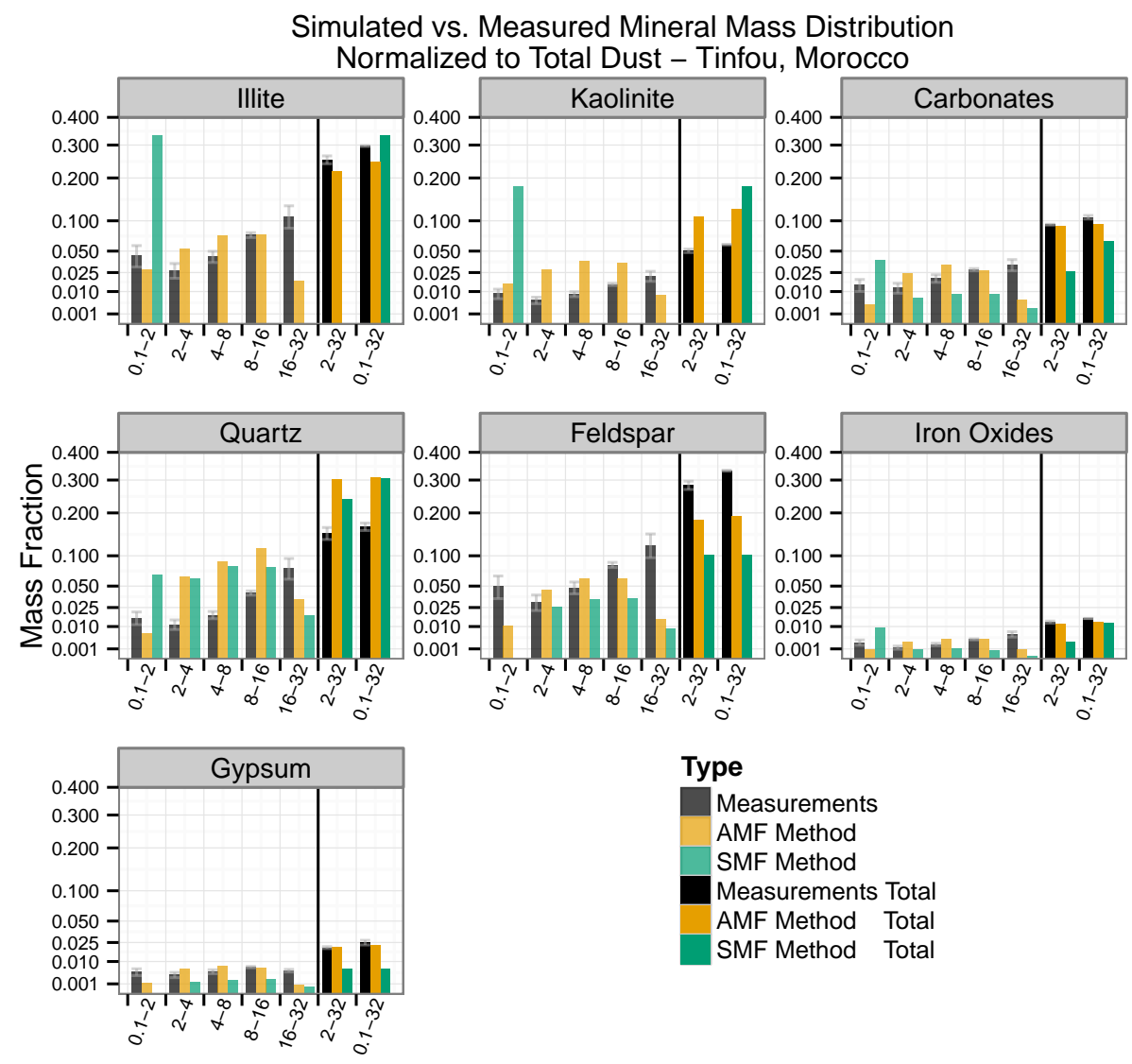

Type

Measurements

AMF Method

SMF Method

Measurements Total

AMF Method Total

SMF Method Total

\section{Size Class $[\mu \mathrm{m}]$}

Figure 17. Same as Fig. 16 but the mineral fractions are relative to the total dust concentration, so that the sum over all mineral fractions and all size bins equals 1 .

An increase of feldspar at larger sizes (with a corresponding decrease at smaller sizes due to our normalization of the size distribution) would confine this mineral more closely to its source region. Conversely, a decrease of phyllosilicates at larger sizes would correspond to greater abundance and transport at smaller sizes. This uncertainty has implications for global climate because both minerals are hypothesized to be effective sites for ice nucleation (Hoose et al., 2008; Atkinson et al., 2013). We will revisit the effects of the uncertain size distribution of both minerals in the companion article (Perlwitz et al., 2015).

\section{Conclusions}

Aerosol mineral composition depends upon the composition of the parent soil and its size fractionation during mobilization. Soil mineral fractions have been estimated by Claquin et al. (1999) using atlases of arid soil type and soil texture derived from measurements following wet sieving. These authors identify the remaining challenge of accounting for the destruction of soil aggregates during wet sieving that results in contrasts between the particle size distribution of both the soil and the emitted aerosols.

We have proposed a heuristic method to reconstruct the size distribution of mineral aggregates that are emitted from the undisturbed soil that is subject to wind erosion. We assume that some of the emitted silt-size particles correspond to the clay-sized fraction of the wet-sieved soil (Eq. 13), whose mineral fractions are estimated by Claquin et al. (1999). Size-resolved measurements of emission provide the distribution of far-travelled particles, whose diameters are below $20 \mu \mathrm{m}$ (cf. Kok, 2011b). We extend the emitted distribution to diameters as large as $50 \mu \mathrm{m}$ to correspond to the size range of the soil mineral fractions, using the normalized volume distribution derived from concentration measurements after transport to Tinfou, Morocco (Kandler et al., 2009).

In addition, we create an additional class of iron oxide aerosol that is a small impurity embedded within other minerals, allowing it to travel farther than in its pure crystalline state. We assume that these impurities are least frequent in soils rich in iron oxides (as a result of the assumed effect of weathering that creates pure iron oxide crystals). Nonetheless, the abundance of iron oxide in these soils means that 
the absolute value of iron oxides in accretions is large. We assume that iron oxides contribute $5 \%$ to the combined particle mass, with the remainder transported as pure crystals that fall out quickly due to their higher density. The resulting global mass fraction of iron oxides that combines accreted and pure forms is just under $2 \%$, a value that we suggest is insensitive to the assumed mass fraction of this mineral in accreted form. Our treatment of iron oxides is constrained by relatively few observations and worthy of more precise future treatments. Modeling of aerosol iron is important for its influence upon several climate processes, including aerosol radiative forcing and marine photosynthesis that modulates atmospheric carbon dioxide.

These extensions define our AMF experiment. In contrast, the SMF experiment serves as a control whose size distribution of the emitted mineral fractions is taken directly from that of the wet-sieved soil and excludes iron accretions. For both experiments, we calculate the regional distribution of minerals using the NASA GISS ModelE2, whose dust size categories range in diameter from 0.1 to $32 \mu \mathrm{m}$.

Emission of clay-sized particles is much smaller in the AMF experiment, due to an observational constraint upon the emitted size distribution. This has implications for longrange transport. Both the SMF and AMF have identical global emission (by construction), but the column load and surface concentration are much lower in the latter experiment, because the particles are larger. Nonetheless, the emission of clay minerals (i.e., phyllosilicates) is only slightly smaller in the AMF experiment. This is a consequence of reaggregation of the wet-sieved soil that results in a substantial fraction of phyllosilicate particles at silt sizes.

In companion articles (Perlwitz et al., 2015; Pérez GarcíaPando et al., 2015), we compare the AMF and SMF experiments to measurements. In the present article, our comparison is limited to the mineral fractions of surface concentration derived from measurements at Tinfou, Morocco (Kandler et al., 2009). These show a majority of the phyllosilicate (or "clay" mineral) mass at silt sizes, consistent with our AMF method. Kandler et al. (2009) note the difficulty of distinguishing phyllosilicates from feldspar in single particle samples due to their limited mass. For this reason, the volume fractions of these two minerals in each size bin are assumed to be identical (cf. Fig. 1). However, these minerals can be distinguished in larger size-integrated samples that reveal comparable masses of each mineral (Kandler et al., 2009). This demonstrates that the presence of phyllosilicate aerosols at diameters larger than $2 \mu \mathrm{m}$ cannot be the result of misattribution of feldspar (because the phyllosilicate mass below this diameter is only a small fraction of the total). The existence of silt-sized phyllosilicates is corroborated by multiple independent measurements (Leinen et al., 1994; Arnold et al., 1998; Reid et al., 2003; Alastuey et al., 2005; Jeong and Nousiainen, 2014).
Both experiments predict comparable fractions of quartz at Tinfou, in spite of the substantially greater silt-sized emission of the AMF method compared to the SMF. This agreement is the result of the reaggregation of clay minerals that reduces the quartz fraction at silt sizes in the undispersed soil prior to emission. This reduction occurs because the total silt emission summed over all minerals is fixed by our empirical constraint Eq. (12). The comparative reduction of quartz in the SMF experiment also occurs because we account for the larger characteristic size of this mineral in the parent soil compared to other minerals. The size distribution of quartz aerosols measured at Tinfou suggests that a disproportionate amount of quartz is at diameters that are too large to be dispersed far from the source. This shows the value of measurements that can distinguish contrasts between the size distributions of different minerals. The distinction between the size distributions of phyllosilicates and feldspar have implications for long-range transport and climate impacts like ice nucleation (Hoose et al., 2008; Atkinson et al., 2013).

In general, our reconstruction of emitted aggregates from the wet-sieved soil allows us to shift clay-sized phyllosilicates toward silt sizes where they are observed and maintain realistic fractions of quartz, despite the observed size distribution of emission that is heavily biased toward silt sizes. We have made little effort to find the optimal amount of reaggregation. Instead, we are developing a more physically based model of reaggregation and brittle fragmentation that extends studies by Kok (2011b) and Scanza et al. (2015), while addressing certain inconsistencies of our present semiempirical approach. For example, we presently reaggregate minerals in proportion to $s_{\mathrm{c}}$, the local fraction of clay-sized particles given by the soil texture atlas, but assume a uniform fraction of clay-sized emission according to Eq. (10) that is independent of this texture. More generally, we will take advantage of more recent estimates of soil mineral fractions (Journet et al., 2014) that use additional measurements to extend the method of Claquin et al. (1999). Singular soil environments like the Bodélé Depression and littoral margins of Lake Chad, where concentrations of diatomite and other constituents derived from biological processes are large, present an additional challenge that results from their significant contribution to global dust emission (Washington et al., 2009). 


\section{Appendix A}

Here we use the assumptions in Sect. 2.2.2 to derive the mass fraction of the iron oxide mixture given by Eq. (30), along with the remaining mass fractions of iron oxides (Eq. 31) and mineral $n$ (Eq. 32) in their pure unmixed state.

We have assumed that accreted iron oxides contribute fraction $R$ to the total mass of the particle mixture via Eq. (26). For small enough prescribed fractions of accretion $(R \ll 1)$, there will be an insufficient amount of the other mineral to combine with the amount of iron oxides specified by Eq. (25). This follows from Eq. (19):

$a_{n, k}^{\operatorname{mix}} \leq a_{n, k}$,

so that from Eq. (26),

$a_{\mathrm{Fe} \mid n, k}^{\operatorname{mix}} \leq \frac{R}{1-R} a_{n, k}$.

In general,

$a_{\mathrm{Fe} \mid n, k}^{\operatorname{mix}}=\min \left[\left(1-a_{\mathrm{Fe}, k}\right) a_{\mathrm{Fe}, k} \frac{a_{n, k}}{\bar{a}_{k}}, \frac{R}{1-R} a_{n, k}\right]$.

Then, the emitted mass fraction of the prognostic variable comprised of mineral $n$ and iron oxides is

$a_{n, k}^{\operatorname{mix}}+a_{\mathrm{Fe} \mid n, k}^{\operatorname{mix}}=\min \left[\frac{\left(1-a_{\mathrm{Fe}, k}\right) a_{\mathrm{Fe}, k}}{R} \frac{a_{n, k}}{\bar{a}_{k}}, \frac{a_{n, k}}{1-R}\right]$.
Again, $a_{\mathrm{Fe}, k}$ and $a_{n, k}$ that are inputs to Eqs. (A3) and (30) are given by Eqs. (11)-(16) and (18).

The pure or unmixed mass fraction of each mineral can be derived from Eq. (A3). Using Eqs. (19) and (26), it can be shown that

$a_{n, k}^{\text {pure }}=a_{n, k}-\left(\frac{1-R}{R}\right) a_{\mathrm{Fe} \mid n, k}^{\operatorname{mix}}$

and

$$
\begin{aligned}
a_{\mathrm{Fe}, k}^{\text {pure }} & =a_{\mathrm{Fe}, k}-\sum_{n \neq \text { iron oxide }} a_{\mathrm{Fe} \mid n, k}^{\operatorname{mix}} \\
& =a_{\mathrm{Fe}, k}-\min \left[\left(1-a_{\mathrm{Fe}, k}\right) a_{\mathrm{Fe}, k}, \frac{R}{1-R} \sum_{n \neq \text { iron oxide }} a_{n, k}\right]
\end{aligned}
$$

so that

$a_{\mathrm{Fe}, k}^{\text {pure }}=a_{\mathrm{Fe}, k}-\min \left[\left(1-a_{\mathrm{Fe}, k}\right) a_{\mathrm{Fe}, k}, \frac{R}{1-R} \bar{a}_{k}\right]$.

For the case where the mass fraction of the emitted iron oxides is small enough, so that

$\left(1-a_{\mathrm{Fe}, k}\right) a_{\mathrm{Fe}, k} \leq \frac{R}{1-R} \bar{a}_{k}$,

all the iron oxides available for mixing can be combined with the other minerals, and Eq. (31) reduces to Eq. (24). 


\section{The Supplement related to this article is available online at doi:10.5194/acp-15-11593-2015-supplement.}

Acknowledgements. We thank Paul Ginoux, Konrad Kandler, Natalie Mahowald, Sergio Rodríguez and Rachel Scanza for helpful conversations. This article was improved by the thoughtful comments of Yves Balkanski, Jasper Kok and two additional reviewers. This research was supported by the National Science Foundation (ATM-01-24258), the Department of Energy (DE-SC0006713), the NASA Modeling, Analysis and Prediction Program and the Ministry of Economy and Competitiveness of Spain through the POLLINDUST project (CGL2011-26259). NCEP Reanalysis winds were provided by the Physical Sciences Division at the National Oceanic and Atmospheric Administration Earth System Research Laboratory via http://www.esrl.noaa.gov/psd/. Computational resources were provided by the NASA High-End Computing (HEC) Program through the NASA Center for Climate Simulation (NCCS) at Goddard Space Flight Center. The emitted mineral fractions for the AMF method at native resolution of $5^{\prime} \times 5^{\prime}$ latitude by longitude are available at the website of the NASA Goddard Institute for Space Studies: http://data.giss.nasa.gov/mineralfrac/.

Edited by: Y. Balkanski

\section{References}

Alastuey, A., Querol, X., Castillo, S., Escudero, M., Avila, A., Cuevas, E., Torres, C., Romero, P.-M., Exposito, F., García, O., Diaz, J. P., Van Dingenen, R., and Putaud, J. P.: Characterisation of TSP and PM2.5 at Izaña and Sta. Cruz de Tenerife (Canary Islands, Spain) during a Saharan Dust Episode (July 2002), Atmos. Environ., 39, 4715-4728, doi:10.1016/j.atmosenv.2005.04.018, 2005.

Albani, S., Mahowald, N. M., Perry, A. T., Scanza, R. A., Zender, C. S., Heavens, N. G., Maggi, V., Kok, J. F., and OttoBliesner, B. L.: Improved dust representation in the Community Atmosphere Model, J. Adv. Model. Earth Sys., 6, 541-570, doi:10.1002/2013MS000279, 2014.

Alfaro, S. C. and Gomes, L.: Modeling mineral aerosol production by wind erosion: Emission intensities and aerosol size distributions in source areas., J. Geophys. Res., 106, 18075-18084, doi:10.1029/2000JD900339, 2001.

Arnold, E., Merrill, J., Leinen, M., and King, J.: The effect of source area and atmospheric transport on mineral aerosol collected over the North Pacific Ocean, Global Planet. Change, 18, 137-159, doi:10.1016/S0921-8181(98)00013-7, 1998.

Atkinson, J. D., Murray, B. J., Woodhouse, M. T., Whale, T. F., Baustian, K. J., Carslaw, K. S., Dobbie, S., O'Sullivan, D., and Malkin, T. L.: The importance of feldspar for ice nucleation by mineral dust in mixed-phase clouds, Nature, 498, 355-358, doi:10.1038/nature12278, 2013.

Baker, A. R., Laskina, O., and Grassian, V. H.: Processing and Ageing in the Atmosphere, in: Mineral Dust: A Key Player in the Earth System, edited by: Knippertz, P. and Stuut, J.-B. W., chap. 4, pp. 75-92, Springer Netherlands, Dordrecht, Heidelberg, New York, London, doi:10.1007/978-94-017-8978-3_4, 2014.
Balkanski, Y., Schulz, M., Claquin, T., and Guibert, S.: Reevaluation of Mineral aerosol radiative forcings suggests a better agreement with satellite and AERONET data, Atmos. Chem. Phys., 7, 81-95, doi:10.5194/acp-7-81-2007, 2007.

Bauer, S. E. and Koch, D.: Impact of heterogeneous sulfate formation at mineral dust surfaces on aerosol loads and radiative forcing in the Goddard Institute for Space Studies general circulation model, J. Geophys. Res., 110, D17202, doi:10.1029/2005JD005870, 2005.

Bian, H. and Zender, C. S.: Mineral dust and global tropospheric chemistry: Relative roles of photolysis and heterogeneous uptake, J. Geophys. Res., 108, 4672, doi:10.1029/2002JD003143, 2003.

Bian, H., Prather, M. J., and Takemura, T.: Tropospheric aerosol impacts on trace gas budgets through photolysis, J. Geophys. Res. 108, 4242, doi:10.1029/2002JD002743, 2003.

Cakmur, R. V., Miller, R. L., and Torres, O.: Incorporating the effect of small-scale circulations upon dust emission in an atmospheric general circulation model, J. Geophys. Res., 109, D07201, doi:10.1029/2003JD004067, 2004.

Cakmur, R. V., Miller, R. L., Perlwitz, J., Geogdzhayev, I. V., Ginoux, P., Koch, D., Kohfeld, K. E., Tegen, I., and Zender, C. S. Constraining the magnitude of the global dust cycle by minimizing the difference between a model and observations, J. Geophys. Res., 111, D06207, doi:10.1029/2005JD005791, 2006.

Caquineau, S., Gaudichet, A., Gomes, L., Magonthier, M., and Chatenet, B.: Saharan dust: Clay ratio as a relevant tracer to assess the origin of soil-derived aerosols, Geophys. Res. Lett., 25, 983-986, doi:10.1029/98GL00569, 1998.

Carlson, T. N. and Prospero, J. M.: The Large-Scale Movement of Saharan Air Outbreaks over the Northern Equatorial Atlantic, J. Appl. Meteorol., 11, 283-297, doi:10.1175/15200450(1972)011<0283:TLSMOS>2.0.CO;2, 1972.

Chatenet, B., Marticorena, B., Gomes, L., and Bergametti, G.: Assessing the microped size distributions of desert soils erodible by wind, Sedimentology, 43, 901-911, doi:10.1111/j.13653091.1996.tb01509.x, 1996.

Chen, H., Navea, J. G., Young, M. A., and Grassian, V. H.: Heterogeneous photochemistry of trace atmospheric gases with components of mineral dust aerosol, J. Phys. Chem. A, 115, 490-499, doi:10.1021/jp110164j, 2011.

Chesworth, W., ed.: Encyclopedia of soil science, Encylopedia of Earth Sciences Series, Springer, Dordrecht, Berlin, Heidelberg, New York, doi:10.1007/978-1-4020-3995-9, 2008.

Choate, L. M., Ranville, J. F., Bunge, A. L., and Macalady, D. L.: Dermally adhered soil: 2. Reconstruction of dry-sieve particle-size distributions from wet-sieve data, Integrated Environmental Assessment and Management, 2, 385-390, doi:10.1002/ieam.5630020410, 2006.

Claquin, T., Schulz, M., and Balkanski, Y. J.: Modeling the mineralogy of atmospheric dust sources, J. Geophys. Res., 104, 22243 22256, doi:10.1029/1999JD900416, 1999.

d'Almeida, G. A. and Schütz, L.: Number, Mass and Volume Distributions of Mineral Aerosol and Soils of the Sahara, J. Clim. Appl. Meteorol., 22, 233-243, doi:10.1175/15200450(1983)022<0233:NMAVDO>2.0.CO;2, 1983.

Deboudt, K., Gloter, A., Mussi, A., and Flament, P.: Red-ox speciation and mixing state of iron in individual African dust particles, 
J. Geophys. Res., 117, D12307, doi:10.1029/2011JD017298, 2012.

DeMott, P. J., Sassen, K., Poellot, M. R., Baumgardner, D., Rogers, D. C., Brooks, S. D., Prenni, A. J., and Kreidenweis, S. M.: African dust aerosols as atmospheric ice nuclei, Geophys. Res. Lett., 30, 1732, doi:10.1029/2003GL017410, 2003.

Dentener, F. J., Carmichael, G. R., Zhang, Y., Lelieveld, J., and Crutzen, P. J.: Role of mineral aerosol as a reactive surface in the global troposphere, J. Geophys. Res., 101, 22869-22889, doi:10.1029/96JD01818, 1996.

FAO: Digital Soil Map of the World and Derived Soil Properties, Food and Agriculture Organization, Rome, Italy, 1995.

FAO: Digital Soil Map of the World, Food and Agriculture Organization, Rome, Italy, 2007.

FAO/IIASA/ISRIC/ISSCAS/JRC: Harmonized World Soil Database (version 1.2), FAO, Rome, Italy and IIASA, Laxenburg, Austria, http://webarchive.iiasa.ac.at/Research/LUC/ External-World-soil-database/HTML/HWSD_Data.html?sb=4 (last access: 24 January 2013), 2012.

Feingold, G., Cotton, W. R., Kreidenweis, S. M., and Davis, J. T.: The Impact of Giant Cloud Condensation Nuclei on Drizzle Formation in Stratocumulus: Implications for Cloud Radiative Properties, J. Atmos. Sci., 56, 4100-4117, doi:10.1175/15200469(1999)056<4100:TIOGCC>2.0.CO;2, 1999.

Frinak, E. K., Mashburn, C. D., Tolbert, M. A., and Toon, O. B.: Infrared characterization of water uptake by low-temperature Namontmorillonite: Implications for Earth and Mars, J. Geophys. Res., 110, D09308, doi:10.1029/2004JD005647, 2005.

Gillette, D. A.: On the production of soil wind erosion aerosols having the potential for long range transport, J. Rech. Atmos, 8, 735744, 1974.

Gillette, D. A., Blifford Jr, I. H., and Fenster, C. R.: Measurements of aerosol size distributions and vertical fluxes of aerosols on land subject to wind erosion, J. Appl. Meteorol., 11, 977-987, doi:10.1175/1520-0450(1972)011<0977:MOASDA>2.0.CO;2, 1972.

Gillette, D. A., Blifford Jr., I. H., and Fryrear, D. W.: The Influence of Wind Velocity on the Size Distributions of Aerosols Generated by the Wind Erosion of Soils, J. Geophys. Res., 79, 4068-4075, doi:10.1029/JC079i027p04068, 1974.

Ginoux, P., Chin, M., Tegen, I., Prospero, J. M., Holben, B., Dubovik, O., and Lin, S.-J.: Sources and distributions of dust aerosols simulated with the GOCART model, J. Geophys. Res., 106, 20255-20273, doi:10.1029/2000JD000053, 2001.

Glaccum, R. A. and Prospero, J. M.: Saharan aerosols over the tropical North Atlantic - Mineralogy, Marine Geology, 37, 295-321, doi:10.1016/0025-3227(80)90107-3, 1980.

Goldstein, H., Reynolds, R., Reheis, M., Yount, J., Lamothe, P., Roberts, H., and McGeehin, J.: Particle Size, CaCO3, Chemical, Magnetic, and Age Data from Surficial Deposits in and around Canyonlands National Park, Utah, Open-file report 2005-1186, U.S. Geological Survey, Reston, Virginia, http://pubs.usgs.gov/ of/2005/1186 (last access: 8 September 2014), 2005.

Goodman, A. L., Underwood, G. M., and Grassian, V. H.: A laboratory study of the heterogeneous reaction of nitric acid on calcium carbonate particles, J. Geophys. Res., 105, 29053-29064, doi:10.1029/2000JD900396, 2000.
Grini, A., Zender, C. S., and Colarco, P. R.: Saltation Sandblasting behavior during mineral dust aerosol production, Geophys. Res. Lett., 29, 1868, doi:10.1029/2002GL015248, 2002.

Hatch, C. D., Gierlus, K. M., Schuttlefield, J. D., and Grassian, V. H.: Water adsorption and cloud condensation nuclei activity of calcite and calcite coated with model humic and fulvic acids, Atmos. Environ., 42, 5672-5684, doi:10.1016/j.atmosenv.2008.03.005, 2008.

Hatch, C. D., Greenaway, A. L., Christie, M. J., and Baltrusaitis, J.: Water adsorption constrained Frenkel-Halsey-Hill adsorption activation theory: Montmorillonite and illite, Atmos. Environ., 87, 26-33, doi:10.1016/j.atmosenv.2013.12.040, 2014.

Hoose, C. and Möhler, O.: Heterogeneous ice nucleation on atmospheric aerosols: a review of results from laboratory experiments, Atmos. Chem. Phys., 12, 9817-9854, doi:10.5194/acp-12-98172012, 2012.

Hoose, C., Lohmann, U., Erdin, R., and Tegen, I.: The global influence of dust mineralogical composition on heterogeneous ice nucleation in mixed-phase clouds, Environ. Res. Lett., 3, 025003, doi:10.1088/1748-9326/3/2/025003, 2008.

Ito, A.: Contrasting the effect of iron mobilization on soluble iron deposition to the ocean in the Northern and Southern Hemispheres, J. Meteorol. Soc. Japan, 90A, 167-188, doi:10.2151/jmsj.2012-A09, 2012.

Iversen, J. D. and White, B. R.: Saltation threshold on Earth, Mars and Venus, Sedimentology, 29, 111-119, doi:10.1111/j.13653091.1982.tb01713.x, 1982.

Iversen, J. D., Greeley, R., and Pollack, J. B.: Windblown dust on Earth, Mars and Venus, J. Atmos. Sci., 33, 2425-2429, doi:10.1175/1520-0469(1976)033<2425:WDOEMA>2.0.CO;2, 1976.

Jeong, G. Y.: Bulk and single-particle mineralogy of Asian dust and a comparison with its source soils, J. Geophys. Res., 113, D02208, doi:10.1029/2007JD008606, 2008.

Jeong, G. Y. and Nousiainen, T.: TEM analysis of the internal structures and mineralogy of Asian dust particles and the implications for optical modeling, Atmos. Chem. Phys., 14, 7233-7254, doi:10.5194/acp-14-7233-2014, 2014.

Jickells, T. D., An, Z. S., Andersen, K. K., Baker, A. R., Bergametti, G., Brooks, N., Cao, J. J., Boyd, P. W., Duce, R. A., Hunter, K. A., Kawahata, H., Kubilay, N., laRoche, J., Liss, P. S., Mahowald, P. S. N., Prospero, J. M., Ridgwell, A. J., Tegen, I., and Torres, R.: Global Iron Connections Between Desert Dust, Ocean Biogeochemistry, and Climate, Science, 308, 6771, doi:10.1126/science.1105959, 2005.

Johnson, D. B.: The Role of Giant and Ultragiant Aerosol Particles in Warm Rain Initiation, J. Atmos. Sci., 39, 448-460, doi:10.1175/1520-0469(1982)039<0448:TROGAU>2.0.CO;2, 1982.

Journet, E., Desboeufs, K. V., Caquineau, S., and Colin, J.-L.: Mineralogy as a critical factor of dust iron solubility, Geophys. Res. Lett., 35, L07805, doi:10.1029/2007GL031589, 2008.

Journet, E., Balkanski, Y., and Harrison, S. P.: A new data set of soil mineralogy for dust-cycle modeling, Atmos. Chem. Phys., 14, 3801-3816, doi:10.5194/acp-14-3801-2014, 2014.

Kalnay, E., Kanamitsu, M., Kistler, R., Collins, W., Deaven, D., Gandin, L., Iredell, M., Saha, S., White, G., Woollen, J., Zhu, Y., Leetmaa, A., Reynolds, R., Chelliah, M., Ebisuzaki, W., Higgins, W., Janowiak, J., Mo, K. C., Ropelewski, C., Wang, J., 
Jenne, R., and Joseph, D.: The NCEP/NCAR 40-Year Reanalysis Project, B. Am. Meteorol. Soc., 77, 437-471, doi:10.1175/15200477(1996)077<0437:TNYRP>2.0.CO;2, 1996.

Kandler, K., Benker, N., Bundke, U., Cuevas, E., Ebert, M., Knippertz, P., Rodríguez, S., Schütz, L., and Weinbruch, S.: Chemical composition and complex refractive index of Saharan Mineral Dust at Izanã, Tenerife (Spain) derived by electron microscopy, Atmos. Environ., 41, 8058-8074, doi:10.1016/j.atmosenv.2007.06.047, 2007.

Kandler, K., Schütz, L., Deutscher, C., Ebert, M., Hofmann, H., Jäckel, S., Jaenicke, R., Knippertz, P., Lieke, K., Massling, A., Petzold, A., Schladitz, A., Weinzierl, B., Wiedensohler, A., Zorn, S., and Weinbruch, S.: Size distribution, mass concentration, chemical and mineralogical composition and derived optical parameters of the boundary layer aerosol at Tinfou, Morocco, during SAMUM 2006, Tellus B, 61, 32-50, doi:10.1111/j.16000889.2008.00385.x, 2009.

Kandler, K., Schütz, L., Jäckel, S., Lieke, K., Emmel, C., MüllerEbert, D., Ebert, M., Scheuvens, D., Schladitz, A., Šegvić, B., Wiedensohler, A., and Weinbruch, S.: Ground-based offline aerosol measurements at Praia, Cape Verde, during the Saharan Mineral Dust Experiment: microphysical properties and mineralogy, Tellus B, 63, 459-474, doi:10.1111/j.16000889.2011.00550.x, 2011.

Kelly, J. T., Chuang, C. C., and Wexler, A. S.: Influence of dust composition on cloud droplet formation, Atmos. Environ., 41, 2904-2916, doi:10.1016/j.atmosenv.2006.12.008, 2007.

Koch, D., Jacob, D., Tegen, I., Rind, D., and Chin, M.: Tropospheric sulfur simulation and sulfate direct radiative forcing in the Goddard Institute for Space Studies general circulation model, J. Geophys. Res., 104, 23799-23822, doi:10.1029/1999JD900248, 1999.

Kok, J. F.: Does the size distribution of mineral dust aerosols depend on the wind speed at emission?, Atmos. Chem. Phys., 11, 1014910156, doi:10.5194/acp-11-10149-2011, 2011a.

Kok, J. F.: A scaling theory for the size distribution of emitted dust aerosols suggests climate models underestimate the size of the global dust cycle, P. Natl. Acad. Sci. USA, 108, 1016-1021, doi:10.1073/pnas.1014798108, 2011b.

Koven, C. D. and Fung, I.: Inferring dust composition from wavelength-dependent absorption in Aerosol Robotic Network (AERONET) data, J. Geophys. Res., 111, D14205, doi:10.1029/2005JD006678, 2006.

Krueger, B. J., Grassian, V. H., Cowin, J. P., and Laskin, A.: Heterogeneous chemistry of individual mineral dust particles from different dust source regions: the importance of particle mineralogy, Atmos. Environ., 38, 6253-6261, doi:10.1016/j.atmosenv.2004.07.010, 2004.

Lafon, S., Sokolik, I. N., Rajot, J. L., Caquineau, S., and Gaudichet, A.: Characterization of iron oxides in mineral dust aerosols: Implications for light absorption, J. Geophys. Res., 111, D21207, doi:10.1029/2005JD007016, 2006.

Laurent, B., Marticorena, B., Bergametti, G., Léon, J. F., and Mahowald, N. M.: Modeling mineral dust emissions from the Sahara desert using new surface properties and soil database, J. Geophys. Res.-Atmos. (1984-2012), 113, D14218, doi:10.1029/2007JD009484, 2008.

Leinen, M., Prospero, J. M., Arnold, E., and Blank, M.: Mineralogy of aeolian dust reaching the North Pacific Ocean 1.
Sampling and analysis, J. Geophys. Res., 99, 21017-21023, doi:10.1029/94JD01735, 1994.

Li, J. and Osada, K.: Preferential settling of elongated mineral dust particles in the atmosphere, Geophys. Res. Lett., 34, L17807, doi:10.1029/2007g1030262, 2007.

Lieke, K., Kandler, K., Scheuvens, D., Emmel, C., Von Glahn, C., Petzold, A., Weinzierl, B., Veira, A., Ebert, M., Weinbruch, S., and Schütz, L.: Particle chemical properties in the vertical column based on aircraft observations in the vicinity of Cape Verde Islands, Tellus B, 63, 497-511, doi:10.1111/j.16000889.2011.00553.x, 2011.

Ma, Q., Liu, Y., Liua, C., and He, H.: Heterogeneous reaction of acetic acid on $\mathrm{MgO}, \alpha-\mathrm{Al}_{2} \mathrm{O}_{3}$, and $\mathrm{CaCO}_{3}$ and the effect on the hygroscopic behaviour of these particles, Phys. Chem. Chem. Phys., 14, 8403-8409, doi:10.1039/C2CP40510E, 2012.

Maher, B., Prospero, J., Mackie, D., Gaiero, D., Hesse, P., and Balkanski, Y.: Global connections between aeolian dust, climate and ocean biogeochemistry at the present day and at the last glacial maximum, Earth-Science Reviews, 99, 61-97, doi:10.1016/j.earscirev.2009.12.001, 2010.

Marticorena, B.: Dust Production Mechanisms, in: Mineral Dust: A Key Player in the Earth System, edited by: Knippertz, P. and Stuut, J.-B., chap. 5, pp. 93-120, Springer Netherlands, Dordrecht, Heidelberg, New York, London, doi:10.1007/978-94017-8978-3_5, 2014.

Marticorena, B., Bergametti, G., Gillette, D., and Belnap, J.: Factors controlling threshold friction velocity in semiarid and arid areas of the United States, J. Geophys. Res., 102, 23277-23287, doi:10.1029/97JD01303, 1997.

Matsuki, A., Schwarzenboeck, A., Venzac, H., Laj, P., Crumeyrolle, S., and Gomes, L.: Cloud processing of mineral dust: direct comparison of cloud residual and clear sky particles during AMMA aircraft campaign in summer 2006, Atmos. Chem. Phys., 10, 1057-1069, doi:10.5194/acp-10-1057-2010, 2010.

McFadden, L. D. and Hendricks, D. M.: Changes in the content and composition of pedogenic iron oxyhydroxides in a chronosequence of soils in southern California, Quat. Res., 23, 189-204, doi:10.1016/0033-5894(85)90028-6, 1985.

McTainsh, G. H., Lynch, A. W., and Hales, R.: Particlesize analysis of aeolian dusts, soils and sediments in very small quantities using a Coulter Multisizer, Earth Surf. Process. Landforms, 22, 1207-1216, doi:10.1002/(SICI)10969837(199724)22:13<1207::AID-ESP820>3.0.CO;2-K, 1997.

Mei, F., Zhang, X., Lu, H., Shen, Z., and Wang, Y.: Characterization of MASDs of surface soils in north China and its influence on estimating dust emission, Chin. Sci. Bull., 49, 2169-2176, doi:10.1007/BF03185784, 2004.

Miller, R. L., Tegen, I., and Perlwitz, J.: Surface radiative forcing by soil dust aerosols and the hydrologic cycle, J. Geophys. Res., 109, D04203, doi:10.1029/2003JD004085, 2004.

Miller, R. L., Cakmur, R. V., Perlwitz, J., Geogdzhayev, I. V., Ginoux, P., Koch, D., Kohfeld, K. E., Prigent, C., Ruedy, R., Schmidt, G. A., and Tegen, I.: Mineral dust aerosols in the NASA Goddard Institute for Space Sciences ModelE atmospheric general circulation model, J. Geophys. Res., 111, D06208, doi:10.1029/2005JD005796, 2006.

Miller, R. L., Knippertz, P., Pérez García-Pando, C., Perlwitz, J. P., and Tegen, I.: Impact of Dust Radiative Forcing upon Climate, in: Mineral Dust: A Key Player in the Earth System, edited 
by Knippertz, P. and Stuut, J.-B. W., chap. 13, pp. 327-357, Springer Netherlands, Dordrecht, Heidelberg, New York, London, doi:10.1007/978-94-017-8978-3_13, 2014.

Moosmüller, H., Engelbrecht, J. P., Skiba, M., Frey, G., Chakrabarty, R. K., and Arnott, W. P.: Single Scattering Albedo of Fine Mineral Dust Aerosols Controlled by Iron Concentration, J. Geophys. Res., 117, D11210, doi:10.1029/2011JD016909, 2012.

Murray, B. J., O'Sullivan, D., Atkinson, J. D., and Webb, M. E.: Ice nucleation by particles immersed in supercooled cloud droplets, Chem. Soc. Rev., 41, 6519-6554, doi:10.1039/C2CS35200A, 2012.

Nickovic, S., Vukovic, A., Vujadinovic, M., Djurdjevic, V., and Pejanovic, G.: Technical Note: High-resolution mineralogical database of dust-productive soils for atmospheric dust modeling, Atmos. Chem. Phys., 12, 845-855, doi:10.5194/acp-12-8452012, 2012.

NRCS Soil Survey Staff: U.S. General Soil Map (STATSGO), Natural Resources Conservation Service, United States Department of Agriculture, http://sdmdataaccess.nrcs.usda.gov/ (last access: 11 April 2013), 2012.

Pérez García-Pando, C., Stanton, M. C., Diggle, P. J., Trzaska, S., Miller, R. L., Perlwitz, J. P., Baldasano, J. M., Cuevas, E., Ceccato, P., Yaka, P., and Thomson, M. C.: Soil Dust Aerosols and Wind as Predictors of Seasonal Meningitis Incidence in Niger, Environ. Health Perspect., 122, 679-686, doi:10.1289/ehp.1306640, 2014a.

Pérez García-Pando, C., Thomson, M. C., Stanton, M. C., Diggle, P. J., Hopson, T., Pandya, R., Miller, R. L., and Hugonnet, S.: Meningitis and climate: from science to practice, Earth Perspectives, 1, 1-15, doi:10.1186/2194-6434-1-14, 2014b.

Pérez García-Pando, C., Perlwitz, J. P., Miller, R. L., and Rodriguez, S.: Predicting the mineral composition of dust aerosols: Insights from chemical composition measurements at the Izaña Observatory, Geophys. Res. Lett., in preparation, 2015.

Perlwitz, J. and Miller, R. L.: Cloud cover increase with increasing aerosol absorptivity: A counterexample to the conventional semidirect aerosol effect, J. Geophys. Res., 115, D08203, doi:10.1029/2009JD012637, 2010.

Perlwitz, J. P., Pérez García-Pando, C., and Miller, R. L.: Predicting the mineral composition of dust aerosols - Part 2: Model evaluation and identification of key processes with observations, Atmos. Chem. Phys., 15, 11629-11652, doi:10.5194/acp15-11629-2015.

Prather, M. J.: Numerical Advection by Conservation of Second-Order Moments, J. Geophys. Res., 91, 6671-6681, doi:10.1029/JD091iD06p06671, 1986.

Prigent, C., Tegen, I., Aires, F., Marticorena, B., and Zribi, M.: Estimation of the aerodynamic roughness length in arid and semiarid regions over the globe with the ERS scatterometer, J. Geophys. Res., 110, D09205, doi:10.1029/2004JD005370, 2005.

Rayner, N. A., Parker, D. E., Horton, E. B., Folland, C. K., Alexander, L. V., Rowell, D. P., Kent, E. C., and Kaplan, A.: Global analyses of sea surface temperature, sea ice, and night marine air temperature since the late nineteenth century, J. Geophys. Res., 108, 4407, doi:10.1029/2002JD002670, 2003.

Redmond, H. E., Dial, K. D., and Thompson, J. E.: Light scattering and absorption by wind blown dust: Theory, measurement, and recent data, Aeolian Res., 2, 5-26, doi:10.1016/j.aeolia.2009.09.002, 2010.

Reid, E. A., Reid, J. S., Meier, M. M., Dunlap, M. R., Cliff, S. S., Broumas, A., Perry, K., and Maring, H.: Characterization of African dust transported to Puerto Rico by individual particle and size segregated bulk analysis, J. Geophys. Res., 108, 8591, doi:10.1029/2002JD002935, 2003.

Reynolds, C. A., Jackson, T. J., and Rawls, W. J.: Estimating soil water-holding capacities by linking the Food and Agriculture Organization Soil map of the world with global pedon databases and continuous pedotransfer functions, Water Resour. Res., 36, 3653-3662, doi:10.1029/2000WR900130, 2000.

Rodríguez, S., Alastuey, A., Alonso-Pérez, S., Querol, X., Cuevas, E., Abreu-Afonso, J., Viana, M., Pérez, N., Pandolfi, M., and de la Rosa, J.: Transport of desert dust mixed with North African industrial pollutants in the subtropical Saharan Air Layer, Atmos. Chem. Phys., 11, 6663-6685, doi:10.5194/acp-11-66632011, 2011.

Rubasinghege, G., Ogden, S., Baltrusaitis, J., and Grassian, V. H.: Heterogeneous Uptake and Adsorption of Gas-Phase Formic Acid on Oxide and Clay Particle Surfaces: The Roles of Surface Hydroxyl Groups and Adsorbed Water in Formic Acid Adsorption and the Impact of Formic Acid Adsorption on Water Uptake, J. Phys. Chem. A, 117, 11316-11327, doi:10.1021/jp408169w, 2013.

Russell, L. M., Maria, S. F., and Myneni, S. C. B.: Mapping organic coatings on atmospheric particles, Geophys. Res. Lett, 29, 1779, doi:10.1029/2002GL014874, 2002.

Sassen, K.: Indirect climate forcing over the western US from Asian dust storms, Geophys. Res. Lett., 29, 1465, doi:10.1029/2001GL014051, 2002.

Scanza, R. A., Mahowald, N., Ghan, S., Zender, C. S., Kok, J. F., Liu, X., Zhang, Y., and Albani, S.: Modeling dust as component minerals in the Community Atmosphere Model: development of framework and impact on radiative forcing, Atmos. Chem. Phys., 15, 537-561, doi:10.5194/acp-15-537-2015, 2015.

Scheuvens, D. and Kandler, K.: On Composition, Morphology, and Size Distribution of Airborne Mineral Dust, in: Mineral Dust: A Key Player in the Earth System, edited by: Knippertz, P. and Stuut, J.-B., chap. 2, pp. 15-49, Springer Netherlands, Dordrecht, Heidelberg, New York, London, doi:10.1007/978-94-017-89783_2, 2014.

Scheuvens, D., Kandler, K., Küpper, M., Lieke, K., Zorn, S., Ebert, M., Schütz, L., and Weinbruch, S.: Individual-particle analysis of airborne dust samples collected over Morocco in 2006 during SAMUM 1, Tellus B, 63, 512-530, doi:10.1111/j.16000889.2011.00554.x, 2011.

Schmidt, G. A., Ruedy, R., Hansen, J. E., Aleinov, I., Bell, N., Bauer, M., Bauer, S., Cairns, B., Canuto, V., Ye Cheng, A. D., Faluvegi, G., Friend, A. D., Hall, T. M., Hu, Y., Kelley, M., Kiang, N. Y., Koch, D., Andy A. Lacis, J. L., Lo, K. K., Miller, R. L., Nazarenko, L., Oinas, V., Perlwitz, J., Rind, J. P. D., Romanou, A., Gary L. Russell, M. S., Shindell, D. T., Stone, P. H., Sun, S., Tausnev, N., Thresher, D., and Yao, M.-S.: Present-Day Atmospheric Simulations Using GISS ModelE: Comparison to In Situ, Satellite, and Reanalysis Data, J. Climate, 19, 153-192, doi:10.1175/JCLI3612.1, 2006.

Schmidt, G. A., Kelley, M., Nazarenko, L., Ruedy, R., Russell, G. L., Aleinov, I., Bauer, M., Bauer, S. E., Bhat, M. K., Bleck, 
R., Canuto, V., Chen, Y.-H., Cheng, Y., Clune, T. L., Del Genio, A., de Fainchtein, R., Faluvegi, G., Hansen, J. E., Healy, R. J., Kiang, N. Y., Koch, D., Lacis, A. A., LeGrande, A. N., Lerner, J., Lo, K. K., Matthews, E. E., Menon, S., Miller, R. L., Oinas, V., Oloso, A. O., Perlwitz, J. P., Puma, M. J., Putman, W. M., Rind, D., Romanou, A., Sato, M., Shindell, D. T., Sun, S., Syed, R. A., Tausnev, N., Tsigaridis, K., Unger, N., Voulgarakis, A., Yao, M.S., and Zhang, J.: Configuration and assessment of the GISS ModelE2 contributions to the CMIP5 archive, J. Adv. Model. Earth Sys., 6, 141-184, doi:10.1002/2013MS000265, 2014.

Schulz, M., Prospero, J. M., Baker, A. R., Dentener, F., Ickes, L., Liss, P. S., Mahowald, N. M., Nickovic, S., Pérez García-Pando, C., Rodríguez, S., Sarin, M., Tegen, I., and Duce, R. A.: Atmospheric Transport and Deposition of Mineral Dust to the Ocean: Implications for Research Needs, Environ. Sci. Technol., 46, 10390-10404, doi:10.1021/es300073u, 2012.

Seifert, P., Ansmann, A., Mattis, I., Wandinger, U., Tesche, M., Engelmann, R., Müller, D., Pérez, C., and Haustein, K.: Saharan dust and heterogeneous ice formation: Eleven years of cloud observations at a central European EARLINET site, J. Geophys. Res.-Atmos. (1984-2012), 115, D20201, doi:10.1029/2009JD013222, 2010.

Shangguan, W., Dai, Y., Duan, Q., Liu, B., and Yuan, H.: A global soil data set for earth system modeling, J. Adv. Model. Earth Syst., 6, 249-263, doi:10.1002/2013MS000293, 2014.

Shao, Y.: A model for mineral dust emission, J. Geophys. Res., 106, 20239-20254, doi:10.1029/2001JD900171, 2001.

Shao, Y. and Lu, H.: A simple expression for wind erosion threshold friction velocity, J. Geophys. Res., 105, 22437, doi:10.1029/2000jd900304, 2000.

Shao, Y., Raupach, M. R., and Findlater, P. A.: Effect of Saltation Bombardment on the Entrainment of Dust by Wind, J. Geophys. Res., 98, 12719-12726, doi:10.1029/93JD00396, 1993.

Shao, Y., Raupach, M. R., and Leys, J. F.: A model for predicting aeolian sand drift and dust entrainment on scales from paddock to region, Aust. J. Soil Res., 34, 309-342, doi:10.1071/SR9960309, 1996.

Shao, Y., Ishizuka, M., Mikami, M., and Leys, J. F.: Parameterization of size-resolved dust emission and validation with measurements, J. Geophys. Res., 116, D08203, doi:10.1029/2010JD014527, 2011.

Shi, Z. B., Woodhouse, M. T., Carslaw, K. S., Krom, M. D., Mann, G. W., Baker, A. R., Savov, I., Fones, G. R., Brooks, B., Drake, N., Jickells, T. D., and Benning, L. G.: Minor effect of physical size sorting on iron solubility of transported mineral dust, Atmos. Chem. Phys., 11, 8459-8469, doi:10.5194/acp-11-84592011, 2011.

Shi, Z., Krom, M. D., Jickells, T. D., Bonneville, S., Carslaw, K. S., Mihalopoulos, N., Baker, A. R., and Benning, L. G.: Impacts on iron solubility in the mineral dust by processes in the source region and the atmosphere: A review, Aeolian Res., 5, 21-42, doi:10.1016/j.aeolia.2012.03.001, 2012.

Sokolik, I. N. and Toon, O. B.: Direct radiative forcing by anthropogenic airborne mineral aerosols, Nature, 381, 681-683, doi:10.1038/381681a0, 1996

Sokolik, I. N. and Toon, O. B.: Incorporation of mineralogical composition into models of the radiative properties of mineral aerosol from UV to IR wavelengths, J. Geophys. Res., 104, 9423-9444, doi:10.1029/1998JD200048, 1999.
Sow, M., Alfaro, S. C., Rajot, J. L., and Marticorena, B.: Size resolved dust emission fluxes measured in Niger during 3 dust storms of the AMMA experiment, Atmos. Chem. Phys., 9, 38813891, doi:10.5194/acp-9-3881-2009, 2009.

Sullivan, R. C., Guazzotti, S. A., Sodeman, D. A., Tang, Y., Carmichael, G. R., and Prather, K. A.: Mineral dust is a sink for chlorine in the marine boundary layer, Atmos. Environ., 41, 7166-7179, doi:10.1016/j.atmosenv.2007.05.047, 2007.

Takahashi, Y., Higashi, M., Furukawa, T., and Mitsunobu, S.: Change of iron species and iron solubility in Asian dust during the long-range transport from western China to Japan, Atmos. Chem. Phys., 11, 11237-11252, doi:10.5194/acp-1111237-2011, 2011.

Tegen, I. and Fung, I.: Modeling of mineral dust in the atmosphere: Sources, transport, and optical thickness, J. Geophys. Res., 99, 22897-22914, doi:10.1029/94JD01928, 1994.

Tegen, I., Hollrig, P., Chin, M., Fung, I., Jacob, D., and Penner, J.: Contribution of different aerosol species to the global aerosol extinction optical thickness: Estimates from model results, J. Geophys. Res., 102, 23895-23915, doi:10.1029/97JD01864, 1997.

Turner, D. D.: Ground-based infrared retrievals of optical depth, effective radius, and composition of airborne mineral dust above the Sahel, J. Geophys. Res., 113, D00E03, doi:10.1029/2008JD010054, 2008.

Twohy, C. H., Kreidenweis, S. M., Eidhammer, T., Browell, E. V., Heymsfield, A. J., Bansemer, A. R., Anderson, B. E., Chen, G., Ismail, S., DeMott, P. J., and Heever, S. C. V. D.: Saharan dust particles nucleate droplets in eastern Atlantic clouds, Geophys. Res. Lett., 36, L01807, doi:10.1029/2008GL035846, 2009.

Usher, C. R., Michel, A. E., Stec, D., and Grassian, V. H.: Laboratory studies of ozone uptake on processed mineral dust, Atmos. Environ., 37, 5337-5347, doi:10.1016/j.atmosenv.2003.09.014, 2003.

Wagner, R., Ajtai, T., Kandler, K., Lieke, K., Linke, C., Müller, T., Schnaiter, M., and Vragel, M.: Complex refractive indices of Saharan dust samples at visible and near UV wavelengths: a laboratory study, Atmos. Chem. Phys., 12, 2491-2512, doi:10.5194/acp-12-2491-2012, 2012.

Washington, R., Bouet, C., Cautenet, G., Mackenzie, E., Ashpole, I., Engelstaedter, S., Lizcano, G., Henderson, G. M., Schepanski, K., and Tegen, I.: Dust as a tipping element: the Bodélé Depression, Chad, P. Natl. Acad. Sci. USA, 106, 20564-20571, doi:10.1073/pnas.0711850106, 2009.

Webb, R. S., Rosenzweig, C. E., and Levine, E. R.: Specifying land surface characteristics in general circulation models: Soil profile data set and derived water-holding capacities, Global Biogeochem. Cycles, 7, 97-108, doi:10.1029/92GB01822, 1993.

Wesely, M. L. and Hicks, B. B.: Some factors that affect the deposition rates of sulfur dioxide and similar gases on vegetation, J. Air Pollut. Control Assoc., 27, 1110-1116, doi:10.1080/00022470.1977.10470534, 1977.

Yakobi-Hancock, J. D., Ladino, L. A., and Abbatt, J. P. D.: Feldspar minerals as efficient deposition ice nuclei, Atmos. Chem. Phys., 13, 11175-11185, doi:10.5194/acp-13-11175-2013, 2013.

Zimmermann, F., Weinbruch, S., Schütz, L., Hofmann, H., Ebert, M., Kandler, K., and Worringen, A.: Ice nucleation properties of the most abundant mineral dust phases, J. Geophys. Res., 113, D23204, doi:10.1029/2008JD010655, 2008. 